\title{
Interaction of dietary compounds, especially polyphenols, with the intestinal microbiota: a review
}

\author{
Aleksandra Duda-Chodak · Tomasz Tarko • \\ Pawel Satora $\cdot$ Paweł Sroka
}

Received: 15 May 2014 / Accepted: 30 January 2015 / Published online: 12 February 2015

(c) The Author(s) 2015. This article is published with open access at Springerlink.com

\begin{abstract}
The intestinal microbiome plays an important role in the metabolism of chemical compounds found within food. Bacterial metabolites are different from those that can be generated by human enzymes because bacterial processes occur under anaerobic conditions and are based mainly on reactions of reduction and/or hydrolysis. In most cases, bacterial metabolism reduces the activity of dietary compounds; however, sometimes a specific product of bacterial transformation exhibits enhanced properties. Studies on the metabolism of polyphenols by the intestinal microbiota are crucial for understanding the role of these compounds and their impact on our health. This review article presents possible pathways of polyphenol metabolism by intestinal bacteria and describes the diet-derived bioactive metabolites produced by gut microbiota, with a particular emphasis on polyphenols and their potential impact on human health. Because the etiology of many diseases is largely correlated with the intestinal microbiome, a balance between the host immune system and the commensal gut microbiota is crucial for maintaining health. Diet-related and age-related changes in the human intestinal microbiome and their consequences are summarized in the paper.
\end{abstract}

Keywords Bioactive metabolites - Bioavailability · Biotransformation · Digestion · Dysbiosis · Health impact

A. Duda-Chodak $(\bowtie) \cdot$ T. Tarko $\cdot$ P. Satora $\cdot$ P. Sroka Department of Fermentation Technology and Technical Microbiology, Faculty of Food Technology, University of Agriculture in Krakow, ul. Balicka 122, 30-149 Kraków, Poland

e-mail: aduda-chodak@ar.krakow.pl

\section{Introduction}

For many years, it was thought that the function of the large intestine was to reabsorb water and salt and remove unused food debris. It is now evident that the intestinal microbiota plays an important, if not crucial, role in the metabolism of chemical compounds found within foods. The large number of bacteria inhabiting the large intestine forms a highly complex ecosystem called the 'intestinal microbiome'. The word 'microbiome' was first introduced in 2001 to define the collective genomes of the microbiota [1]. In 2007, the 'human microbiome project' was launched with the aim of collecting and integrating genomic information from many diverse human microbiomes and examining the relationship between changes in the human microbiome and various diseases [2, 3]. Growing scientific interest in the composition of the microbiome and its impact on human health has led to the initiation of many similar projects all over the world. The NIH Human Microbiome Project (2007, USA) aimed to characterize the influence of the microbiota on the human body and to correlate changes in these microbial populations with human health. The Irish ELDERMET Project (2007-2013) focused on characterization of the fecal microbiota associated with aging and aimed to correlate the composition, diversity and metabolic potential of the fecal microbial metagenome with health, diet and lifestyle. MetaHIT (metagenomics of the human intestinal tract, 2008-2011) was a European project focused on assessing the role of the microbiota in inflammatory bowel disease and obesity. The French project Microbes (human intestinal microbiome in obesity and nutritional transition, 2008-2010) sought to identify metagenomic signatures that characterize the relationship between the intestinal microbiome and the nutritional and metabolic status of the host. The interactions between intestinal microbes and 
host health were also evaluated by the Australian jumpstart human microbiome project (2009) and Canadian Human Microbiome Initiative (2009). Still in progress is the Korean Microbiome Diversity using Korean Twin Cohort Project (2010-2015) that aims to determine the microbiomes on various epithelial sites of the human body using the Korean twin cohort and to investigate the relationship between the human microbiome and disease.

The aim of this article is to review recent studies on factors affecting the composition of the human gut microbiota with a particular emphasis on polyphenolic compounds. The manuscript presents a compilation of the knowledge on functional aspects of the normal gut microbiota from two perspectives: (1) the role of particular microbial species in the metabolism of polyphenols and (2) a detailed insight into the role of biotransformation of polyphenols in relation to their beneficial functions on health.

\section{Microbial diversity of the human gut microbiota}

The human gut is colonized by an enormous number of microorganisms, mainly bacteria. It is estimated that the microbiota of a human adult is composed of $\sim 10^{14}$ bacterial cells, which is ten times more than the total number of human cells [4]. The metabolic capacity of the intestinal microbiome is approximately 100 -fold greater than that of the human liver. This is a result of the great diversity of bacterial species forming the population, and hence the large number of genes which they contain [4].

The process of gut colonization starts immediately after birth. The infant's microbiota initially shows instability and low diversity, evolving into a more stable adult-type microbiota after the first 2-4 years of life. Its final composition depends on environmental factors. According to Sakata et al. [5] in the first week of human life enterobacteria, streptococci, enterococci and staphylococci are already present in the infant's gut while anaerobes such as bifidobacteria, lactobacilli and Bacteroides spp. are not. The gradual consumption of oxygen in the intestine by aerobic microorganisms provides conditions for the settlement of anaerobic bacteria. Breastfeeding is a significant factor in the determination of the neonatal gut microbiota. In full-time breastfed babies (1 month old), bifidobacteria constituted a predominant group in the feces, while in formula-fed infants, although bifidobacteria were also the predominant species, other bacteria such as enterobacteria, enterococci, lactobacilli, clostridia and Bacteroides spp. were present in significantly higher numbers compared with breastfed infants $[6,7]$.

Initial colonization of the intestine does not appear to be random but rather 'pre-programmed'. Although host genetics can predict microbial composition to an extent, several extrinsic factors (mode of infant delivery, antibiotic exposure, neonatal nutrition, adult nutrition, stress, age, degree of hygiene, bacterial infections) contribute to the development of an individual's unique microbial composition and as a result, susceptibility to several diseases $[8,9]$. It has been shown that infants born vaginally acquire their own mother's vaginal and intestinal flora (dominated by Lactobacillus, Prevotella, Atopobium or Sneathia spp.) and have higher levels of Clostridium spp, while infants delivered by cesarean section have increased levels of skin-associated bacteria including Staphylococcus, Corynebacterium and Propionibacterium spp. [7, 10, 11].

The microbiota of the human gastrointestinal tract starts in the mouth, and the number of viable cells is estimated at $10^{8}-10^{10}$ colony-forming units (CFU) of bacteria per gram of saliva. As a result of the swallowing reflex, these bacteria are continuously transferred to the subsequent parts of the gastrointestinal tract. The number of microorganisms is significantly reduced in the stomach $\left(\sim 10^{3} \mathrm{CFU} / \mathrm{g}\right.$ gastric juice), duodenum and jejunum $\left(10^{2}-10^{4} \mathrm{CFU} / \mathrm{g}\right.$ content), increasing again in the ileum and colon (approximately $10^{10} \mathrm{CFU} / \mathrm{g}$ content and $10^{10}-10^{12} \mathrm{CFU} / \mathrm{g}$ content, respectively) [12]. The enormous number of microorganisms that inhabit the human large intestine (up to $10^{12}$ bacteria per gram of colonic content) is the highest accumulation of microorganisms in the environment that has been reported to date [13].

The composition, as well as the ratio of different species that form the intestinal microbiome, is very diverse within the human population [14]. The composition of the human gut ecosystem is influenced by multiple and diverse factors, such as age, origin, environment, dietary habits (including probiotics) and the application of antibiotics. Hence, each individual has his or her own unique profile of microbial species, which can be compared to a fingerprint. Owing to the multitude of direct and indirect interactions with the host organism, the intestinal microbiome is closely linked to the health of the host $[15,16]$.

Evidence from culture-based studies led to the number of bacterial species in the human intestinal microbiome being estimated at approximately 400-500. However, only a small proportion of bacteria can be easily cultivated in vitro. Consequently, the major populations identified in stool samples were composed of bacteria that can grow quickly in classical high-nutrient growth media at mesophilic temperatures. Moreover, such studies were usually conducted in anaerobic conditions, whereas some gut bacteria prefer microaerophilic growth. Development of molecular methods of bacterial diversity assessment has enabled these limitations to be overcome. Since the year 2000, large-scale 16S rRNA or metagenomic studies have allowed scientists to improve their knowledge regarding the diversity of the human gut microbiome $[17,18]$. It is 
commonly accepted that $\sim 80 \%$ of the bacteria identified by molecular tools in the human gut are uncultured and hence can be characterized only by metagenomic studies $[17,19]$. Qin et al. [20] found that there are 1,000-1,150 prevalent bacterial species, and each individual harbors at least 160 species.

There are significant inter-individual differences in the bacterial species found in the gastrointestinal tract, and these differences are a result of the age, health, diet or geographical location of the individual. On the basis of $16 \mathrm{~S}$ rRNA analysis of intestinal microbiota samples taken from different individuals, it has been shown that, despite the great diversity of bacterial species, the majority ( $98 \%$ of all species) belong to only four bacterial phyla: Firmicutes (64\%), Bacteroidetes (23\%), Proteobacteria (8\%) and Actinobacteria (3\%), whereas other minor taxonomic divisions are quite diverse [4, 21, 22]. It should be emphasized that the ratio between these groups is strongly dependent on the location within the intestine, and on the ethnicity of the host. Firmicutes and Bacteroidetes dominate in the large intestine, while in the jejunum Proteobacteria are more abundant than Bacteroidetes. In the ileum of Japanese adults, no Bacteroidetes were detected, whereas these bacteria dominated the microbiota of healthy Swedish women $[12,23,24]$.

\section{Changes of the intestinal microbiota}

Age-related changes

The microbiota composition is not stable over the life of an individual. It is natural that the diet of elderly individuals changes for many reasons, including loss of sensation of taste and smell, tooth loss, and chewing difficulties, or due to certain diseases that result in the exclusion of certain components from the diet (cholesterol, sugar, salt). Some of these age-related microbiota composition changes may therefore be attributable to diet. However, composition of the intestinal microbiota may also vary in elderly subjects independently of diet because of a number of physiological and immunological factors, such as reduced functionality of the immune system. It has been shown that the microbiota associated with elderly individuals is characterized by reduced abundance of Ruminococcus and Blautia spp. and a diminished abundance of several butyrate producers, while the number of Escherichia is increased compared with young controls [25]. The ratio of Firmicutes over Bacteroidetes $(\mathrm{F} / \mathrm{B})$ is one of the parameters known to change throughout the lifespan. The ratio is lower in the first year of life (0.4), increases in adulthood (10.9), and decreases during old age (0.6) [26]. Recently, it has been demonstrated that the gut microbiota in adolescent children
11-18 years of age differs from that of adults, with significantly higher abundance of Bifidobacterium and Clostridium genera [27]. These results indicate that adolescent children should be considered a separate age-group in this field of research.

It is notable that the ratio of Firmicutes to Bacteroidetes is higher in obese than in lean humans. Moreover, this proportion decreases with weight loss on a low-calorie diet [28]. This means that in addition to the effect of excess calories per se, a high-calorie diet predisposes to obesity through microbiota modulation, which manifests by the increased F/B ratio. Hence, the F/B ratio may also be considered a useful biomarker of obesity [29].

\section{Diet-related dysbiosis}

A balance between the host immune system and the commensal gut microbiota is crucial for maintaining health. If this balance is disturbed (dysbiosis), the host-microbe relationship can progress toward disease $[14,30]$. Dysbiosis can be diet-related [19]. It is now clear that microbes present in the human gut are essential for the process of digestion in the host. During anaerobic fermentation, their metabolism causes a breakdown of indigestible compounds such as resistant starch and plant polysaccharides, which results in short-chain fatty acid (SCFA) production. Other examples of microbe-specific metabolism are the syntheses of vitamins and amino acids [14]. In contrast, some compounds present in the diet can modulate the microbiota composition, resulting in changes in the metabolic activity of intestinal bacteria [31].

\section{Specific diets}

The composition of the gut microbiota is susceptible to the quality and quantity of ingested carbohydrates that are the main carbon and energy source for the microbes. Any diet that is either selective or defective with respect to its nutrient content will cause the disruption of the delicate balance between the host and its intestinal microbiota, leading to diet-related dysbiosis. Such a situation may subsequently favor the overgrowth of opportunistic pathogens and weaken the host defense against infection and chronic inflammation, possibly via alterations in mucosal immunity.

In studies of the intestinal microbiota in humans with celiac disease, the numbers of aerobic Staphylococcus, as well as anaerobic Clostridium and Bacteroides, were significantly higher $(p<0.05)$ than in healthy subjects. In contrast, the number of Bifidobacteria was slightly higher in healthy controls [32]. A gluten-free diet (GFD) is a type of diet used for celiac disease treatment. It has been shown that a GFD itself could lead to modifications of the 
composition and immune properties of the gut microbiota. In the study of Sanz [33], ten healthy subjects (30.3 years old) consumed a GFD for 1 month by replacing glutencontaining foods that they usually ate with certified glutenfree foods. Analyses of their fecal microbiota and dietary intakes demonstrated that populations of Bifidobacterium and Lactobacillus (generally regarded as healthy bacteria) decreased, while populations of potentially unfavorable bacteria such as Escherichia coli and total Enterobacteriaceae increased; this occurred in parallel with reductions in the intake of polysaccharides. A diet rich in the fructantype resistant starches, especially oligofructose and inulin, is known to promote "good" species of colon bacteria [34]. Such prebiotics are found in the diet mainly in association with wheat, barley and onions [35]. This means that a GFD could cause similar, potentially adverse changes in the microbiota solely on the basis of a significant reduction in fructan intake. Provision of gluten-free but prebiotic-rich foods, or diet supplementation with fructan-type prebiotics, could help avoid these adverse effects and provide important support to the intestinal microbiota of people with celiac disease.

Other researchers have focused on differences in the fecal microbiota of neonates that were fed either breast milk or formula. Many studies have shown that breastfeeding results in the development of an intestinal microflora rich in Bifidobacteria and Lactobacillus, while formula-fed infants are colonized more often with E. coli, Clostridium difficile, members of the Bacteroides fragilis group and Lactobacilli $[6,7,36]$.

The impact of diet on microbiota composition was also examined by De Filippo et al. [29]. They demonstrated that the fecal microbiota in a cohort of Italian children was different to that found in children in a rural village in Burkina Faso (BF). BF children showed a significant enrichment in Bacteroidetes and depletion in Firmicutes, with a unique abundance of bacteria from the genera Prevotella, Treponema and Xylanibacter, known to contain a set of bacterial genes for cellulose and xylan hydrolysis, which were completely lacking in the Italian children. In addition, significantly more SCFAs were found in BF than in Italian children, whereas Enterobacteriaceae (Shigella and Escherichia) were significantly underrepresented. The authors hypothesized that the gut microbiota have coevolved with the long-term polysaccharide-rich diet of BF individuals, allowing them to maximize energy intake from dietary fiber, and protecting against inflammation and noninfectious colonic disease. They also suggested a potential impact of the "Western diet" on the colonization and establishment of the intestinal microbiota in European and other developed countries.

Similar adaptation of microbiota to a specific diet was demonstrated in the gut microbiome of Japanese individuals, which is the only microbiome to date shown to possess the porphyranase genes. Hehemann et al. [37] suggested that those enzymes, which are involved in the carbohydrate metabolic pathway of porphyran from marine red algae, were most likely acquired by the human gut microbiota through horizontal gene transfer from marine microbes. These results are concordant with the fact that Japanese people have a tradition of eating foods containing raw seaweed (such as nori, the edible seaweed of the red algae genus Porphyra that is used in preparing sushi) and this is suggested as the reason for the presence of porphyranases in Japanese but not American gut microbiota [37, 38].

Another example of when long-term dietary practices affect the composition of the resident microbiota was demonstrated for developed countries and the so-called Western diet, which is high in sugar and fat. This diet can cause dysbiosis by increasing the number of Clostridium innocuum, Eubacterium dolichum, Catenibacterium mitsuokai and Enterococcus spp. and decreasing Bifidobacteria and Bacteroidetes [9, 39, 40]. Wu et al. [41] showed that the Bacteroides enterotype was highly associated with a diet rich in animal protein, particular types of amino acids and saturated fats, which suggests that meat consumption (as in a Western diet) characterized this enterotype. In contrast, the Prevotella enterotype was associated with high values for carbohydrates and simple sugars, indicating association with a carbohydrate-based diet more typical of agrarian societies. These results confirmed conclusions from a previous study, in which overweight adolescents were subjected to a calorie-restricted diet (10-40\%) and increased physical activity (15-23 kcal/kg body weight/wk) over 10 weeks [42]. The intervention led to increased numbers of $B$. fragilis and Lactobacillus groups, and decreased numbers of the Clostridium coccoides group, Bifidobacterium longum and $B$. adolescentis. The role of changes in gut composition in the development of obesity was examined in an Egyptian population [43]. The results confirmed that the numbers of bacteria from the phyla Firmicutes and Bacteroidetes were statistically significantly increased in the obese group compared with the normal weight group. Moreover, a trend for subjects with high fat intake to have positive Firmicutes, and those with the highest carbohydrate intake to have positive Bacteroidetes and Firmicutes, was also observed.

Vegetarianism is a diet that can modulate the intestinal microbiota in humans because of the high amounts of fiber consumed. It results in increased SCFA production by microbes [44], which can decrease intestinal pH. Indeed, subjects on a vegan or vegetarian diet showed significantly lower intestinal and stool $\mathrm{pH}$, which prevented the growth of potentially pathogenic bacteria such as $E$. coli and other members of the Enterobacteriaceae [45]. Significantly lower total counts of Bacteroides spp., Bifidobacterium spp., E. coli and Enterobacteriaceae spp. in vegan samples 
was demonstrated compared with controls. Enrichment of Prevotella versus Bacteroides was also shown for vegetarians as well as for individuals who consume a high proportion of fruit and vegetables and a low proportion of meat. The reverse was associated with a diet that contains a low proportion of plant-based foods [25, 41]. Dietary interventions designed to promote SCFA production in the colon may therefore have some efficacy in the treatment of dysbiosis.

\section{Impact of diet-derived nutraceuticals on the microbiota}

\section{Polyphenols}

Many studies have examined the potential effects of polyphenols against pathogens. However, there are notably few studies investigating the influence of polyphenols on the composition and activity of the nonpathogenic gut microbial community. The most potent inhibitors of microorganism growth are probably the polyphenolic compounds from green and black tea. It has been shown that the bioactive components of tea, which include epigallocatechin gallate, epicatechin gallate, epigallocatechin, gallocatechin, epicatechin and catechin [46], can inhibit the growth of many pathogens including Helicobacter pylori [47], Staphylococcus aureus, E. coli O157:H7 [48, 49], Salmonella typhimurium DT104, Listeria monocytogenes, methicillin-resistant S. aureus [50, 51], Pseudomonas aeruginosa [52], hepatitis C virus [53], influenza virus [54], HIV [55-57], EpsteinBarr virus [53] and fungi of the Candida genus [58]. Some studies suggest that polyphenols can stimulate the growth of commensal and beneficial microbiota while pathogenic strains are inhibited. For example, the growth of certain pathogenic bacteria such as Clostridium perfringens, $C$. difficile and Bacteroides spp. was significantly inhibited by tea phenolics and their derivatives, while commensal anaerobes such as Clostridium spp., Bifidobacterium spp. and probiotics such as Lactobacillus spp. were less severely affected [59].

The inhibitory effect of citrus polyphenols such as hesperetin, naringenin, poncirin and diosmetin on the growth of $H$. pylori [60] has also been demonstrated. Parkar et al. [61] investigated the effect of common dietary polyphenols on the growth of the human gut bacteria and their adhesion to enterocytes. All of the polyphenols analyzed, except rutin, were found to affect the viability of representative gut microflora in vitro at doses likely to be present in the gastrointestinal tract, but to different degrees. Naringenin and quercetin were the most active with the lowest minimum inhibitory concentrations for all of the four bacteria tested (Lactobacillus rhamnosus, E. coli, S. aureus and S. typhimurium). Naringenin and phloridzin were the most effective inhibitors of $S$. typhimurium adherence to Caco-2 enterocytes, while phloridzin and rutin enhanced the adherence of the probiotic L. rhamnosus. Polyphenols thus appear to be able to alter gut microecology and, by affecting the total number of beneficial species in the gut, may confer positive gut health benefits. In another study, it was demonstrated that both rutin and quercetin inhibited the growth of the pathogenic bacteria E. coli and Serratia marcescens, while only quercetin had an inhibitory impact on Klebsiella pneumonia and Proteus vulgaris [62]. Differences between the actions of polyphenols belonging to the same group (flavonols or flavanones) are probably dependent on the 4-carbonyl group in the $\mathrm{C}$ ring of the flavonoid skeleton. The results of Duda-Chodak [31] suggest that the presence of this group is critical for the inhibitory activity of flavonols and flavanone aglycones. It was demonstrated that flavonoid aglycones (at doses $4-250 \mu \mathrm{g} / \mathrm{ml}$ ), but not their glycosides, may inhibit growth of some intestinal bacteria. In this study, rutin had no inhibitory influence on the intestinal bacteria analyzed, and even slight stimulation of the growth of Lactobacillus spp. was observed. In contrast, its aglycone quercetin exerted a dose-depended inhibitory effect (except on Bifidobacterium catenulatum), and this was especially strong on Ruminococcus gauvreauii, Bacteroides galacturonicus and Lactobacillus spp. (MIC $20-50 \mu \mathrm{g} / \mathrm{ml}$ ) growth. The same was true for flavanones. Naringin and hesperidin (flavanone glycosides) had no impact, but their aglycones (naringenin and hesperetin, respectively) inhibited growth of almost all bacteria analyzed (MIC $\geq 250 \mu \mathrm{g} / \mathrm{ml}$ ). In the same study, catechin had no influence on tested representatives of human intestinal microbiota. (+)-Catechin has been shown to significantly inhibit growth of Clostridium histolyticum [63]; however, the impact of catechin on Clostridium depends on the species. In cultures with $(+)$-catechin, statistically significant increases in the growth of the $C$. coccoides-Eubacterium rectale group, Bifidobacterium spp. and $E$. coli, as well as a significant inhibitory effect on the growth of the $C$. histolyticum group, have been shown [63]. The significant changes in bacterial composition in response to $(+)$-catechin were accompanied by its rapid conversion to (+)-epicatechin. In contrast, the effect of (-)-epicatechin was less profound, only significantly increasing the growth of the $C$. coccoides $-E$. rectale group.

The growth of Clostridium spp. can be decreased significantly by a tannin-rich diet or red wine polyphenols, while Bacteroides and Lactobacillus will be stimulated in such conditions [64, 65]. In the study of Sanchez-Patan et al. [66], an extract of wine phenolics (rich in quercetin, flavan-3-ols and anthocyanins) had no influence on the Lactobacillus/Enterococcus spp., Bacteroides spp., Bifidobacterium spp. and members of the domain bacteria. An observed slight inhibition in the $C$. histolyticum group was 
not significant. However, red wine polyphenols can influence the gut microbiota. The daily consumption of red wine polyphenols for 4 weeks significantly increased the number of Enterococcus, Prevotella, Bacteroides, Bifidobacterium, Bacteroides uniformis, Eggerthella lenta and Blautia coccoides-E. rectale groups [67].

Flavonols can also modulate the gut microbiota by affecting the adhesion of bacteria to intestinal cells, but the influence of flavan-3-ols on bacterial adhesion differs greatly between compounds, strains and degree of differentiation of intestinal cells [68]. All flavan-3-ols tested significantly inhibited adhesion of Lactobacillus acidophilus LA-5 and Lactobacillus plantarum IFPL379, except epigallocatechin gallate, which enhanced L. acidophilus LA-5 adhesion to Caco-2 cells. Procyanidins B1 and B2 markedly increased the adhesion of Lactobacillus casei LC115 to HT-29 cells, whereas epigallocatechin increased $L$. casei LC115 adhesion to Caco-2 cells.

There are only a few studies that have examined the antibacterial properties of anthocyanins. The anthocyanidins pelargonidin, delphinidin and cyanidin, as well as cyanidin-3-glucoside (C3G), have been shown to inhibit growth of E. coli CM 871, but had no effect on strains of the Lactobacillus and Bifidobacterium genera, Salmonella enterica SH-5014 or Enterococcus faecalis E-203 [69]. It was also found that $\mathrm{C} 3 \mathrm{G}$ inhibited secretion of $\mathrm{CagA}$ and VacA in $H$. pylori via down-regulation of secA expression [70]. This means that a diet abundant in various berries rich in $\mathrm{C} 3 \mathrm{G}$ may be beneficial in reducing gastric inflammation or stomach cancer if these are dependent on $H$. pylori infection. In another study, all of the anthocyanins tested significantly enhanced the growth of Bifidobacterium spp. and Lactobacillus-Enterococcus spp., suggesting that anthocyanins and their metabolites may exert a positive effect on the intestinal bacterial population [71].

Anthocyanins have been shown to stimulate the growth of lactic acid bacteria and increase malolactic fermentation [72]. These bacteria can cleave the anthocyanin molecules and use the sugar moiety as a carbohydrate source. Cranberries, a fruit rich in proanthocyanidins, are used for maintaining urinary tract health. It is thought that the beneficial effect of cranberry is due to antiadhesion activity against both antibiotic-susceptible and antibiotic-resistant strains of uropathogenic P-fimbriated E. coli [73]. It has been shown that cranberry proanthocyanidins have unusual A-type linkages [74] compared with the more common B-type linkages found in proanthocyanidins from other tannin-rich foods. Howell et al. [75] postulated that this is the reason why cranberry consumption prevents urinary tract infections while other foods containing only B-linked proanthocyanidin do not. There are no data to date on the antiadhesion activity of B-linked proanthocyanidins.
All of the results described above confirm that polyphenols can modulate the composition of the intestinal microbiota and hence indirectly influence their own metabolism and bioavailability.

\section{Prebiotics}

Diets abundant in plant polysaccharides contain resistant starch and oligosaccharides that undergo bacterial fermentation in the intestine. Indigestible by the host, complex polysaccharides are converted by the primary degrader bacteria resulting in the release of a wide range of SCFAs (mainly acetate, propionate and butyrate) and a number of other metabolites (lactate, pyruvate, ethanol, succinate, soluble oligosaccharides, gases) that are the "fuel" for secondary degrader bacteria [76-78]. Changes in the intestinal microbiota observed in individuals that switch to a GFD can be explained by the reduction in polysaccharide intake. High intake of dietary fiber results in a greater SCFA concentration and lower $E$. coli counts in mammalian intestine, while an opposite trend has been shown with low fiber intake [33].

Bacterial fermentation products can be used as nutrients, as well as growth signals for the intestinal epithelium. For example, butyrate (which has prodifferentiation, antiproliferation and antiangiogenic effects on colonocytes [79]) is utilized by those cells as a major energy substrate; acetate is mainly metabolized in human muscle, kidney, heart and brain; and propionate is cleared by the liver [80].

A nondigestible food ingredient that beneficially affects the host by selectively stimulating the growth and/or activity of one or a limited number of bacteria in the colon, and thus improves host health, is called a prebiotic [81]. A more recent definition of a prebiotic is "a selectively fermented ingredient that allows specific changes, both in the composition and/or activity in the gastrointestinal microflora, that confer benefits upon host well-being and health" [82]. In order for a food ingredient to be classified as a prebiotic, it must satisfy four criteria: (1) be neither hydrolyzed nor absorbed in the upper part of the gastrointestinal tract; (2) be a selective substrate for one or a limited number of beneficial bacteria commensal to the colon, which are stimulated to grow and/or are metabolically activated; (3) consequently, be able to alter the colonic flora in favor of a healthier composition; and (4) induce luminal or systemic effects that are beneficial to the host's health. Among the food ingredients, nondigestible carbohydrates (oligo- and polysaccharides), some peptides and proteins, and certain lipids (both ethers and esters) are candidate prebiotics. Because of their chemical structure, these compounds are not absorbed in the upper part of the gastrointestinal tract nor hydrolyzed by human digestive enzymes. Nondigestible lipids that naturally occur in the diet have not yet been 
examined in this context, and their metabolism and beneficial effect on host health is still theoretical. In the case of proteins that reach the colon, their anaerobic proteolysis generates a range of metabolites including the branchedchain fatty acids such as isobutyrate, isovalerate and isocaproate, as well as indoles, phenolic compounds, sulfides, ammonium, histamine and oxaloacetate. These putrefactive products are generally considered to be toxic and to cause adverse effects on the colonic epithelium [81, 82], so proteins are not considered viable as prebiotics. Most promising prebiotics are nondigestible oligosaccharides, including fructooligosaccharides, galactooligosaccharides (GOS) and inulin. Trans-galactooligosaccharides are a mixture of oligosaccharides derived from the enzymatic transglycosylation of lactose. The selective growth stimulation of Bifidobacterium and Lactobacillus by GOS has been shown [83-86] along with a significant decrease in the concentration of Bacteroides, Candida [83] and Enterobacteriaceae [84]. Lactulose, which is one of the best characterized prebiotic components produced by the isomerization of lactose, selectively stimulated growth of Bifidobacterium, Lactobacillus and Streptococcus, whereas numbers of $C$. perfringens, Bacteroides and Enterobacteriaceae were reduced [82].

Supplementation of fecal specimens with lactulose and blood decreased toxic short-chain (iC4-nC6) fatty acid (isobutyrate, butyrate, isovalerate, valerate, isocaproate and caproate) production and increased acetate and lactate production, resulting in increased fecal acidity. These changes were statistically significant when compared with supplementation with blood alone and correlated with the reduction in the growth of $C$. difficile and Bacteroides spp. [87].

Inulins are common plant storage carbohydrates that are nutritionally classified as dietary fibers. Inulin-type fructans are present in a range of different plants including wheat, onion, banana, garlic, leek and Agave tequilana [80]. Numerous in vitro and in vivo studies have demonstrated that inulin and oligofructose selectively stimulate the health-promoting groups of human intestinal microbiota, Bifidobacterium and Lactobacilli [88]. Administration of inulin and oligofructose, either alone or as a synbiotic, has been shown to selectively increase numbers of bifidobacteria in the luminal and mucosa-associated microbiota, typically representing a prebiotic effect [88-90]. Both in vitro and in vivo studies have demonstrated that the colonic fermentation of inulin-type fructans increases the production of butyrate, which is the so-called butyrogenic effect. This can be explained by bacterial cross-feeding; i.e., lactate produced by Bifidobacterium adolescentis is converted to butyrate by Eubacterium hallii and Anaerostipes caccae (both Firmicutes). The latter bacterium can also utilize released fructose monomers to produce butyrate $[91,92]$.
Polyunsaturated fatty acids

Polyunsaturated fatty acids (PUFAs) include, among others, the $\omega-3$ fatty acids (linolenic, eicosapentaenoic and docosahexaenoic acids) and $\omega-6$ fatty acids (linoleic and arachidonic acids). Some interactions of PUFAs with the gut microbiota or with certain probiotics have been reported. In vitro studies on the effects of free linoleic, $\gamma$-linolenic, arachidonic, $\alpha$-linolenic and docosahexaenoic acids at concentrations of $10-40 \mu \mathrm{g} / \mathrm{ml}$ demonstrated the inhibition of growth and mucus adhesion of the probiotics L. rhamnosus GG and L. casei Shirota as well as Lactobacillus delbrueckii subsp. bulgaricus (dairy strain). PUFAs also altered bacterial adhesion sites on Caco-2 cells [93]. In contrast, when linoleic acid and $\alpha$-linolenic acid were added to medium with various Bifidobacterium species, their conversion to conjugated linoleic acid (CLA) and conjugated linolenic acid isomers, respectively, started immediately [94]. There is growing interest in CLA because both beneficial and detrimental effects for human health have been reported $[95,96]$.

\section{Diet-derived bioactive metabolites produced by gut microbiota and their potential impact on human health}

The intestinal microbiota is equipped with a large set of different enzymes capable of various modifications of food ingredients that enter the colon. It can hydrolyze glycosides, glucuronides, sulfates, amides, esters and lactones through the action of enzymes such as $\alpha$-rhamnosidase, $\beta$-glucuronidase, $\beta$-glucosidase, sulfatase and esterases. Other reactions catalyzed by the gut microbial enzymes are aromatic ring cleavage, reductions (reductases, hydrogenases), decarboxylation (decarboxylase), demethylation (demethylase), isomerization (isomerase) and dehydroxylation (dehydroxylase) $[97,98]$. This large and diverse enzymatic capacity generates various metabolites that have both beneficial and detrimental effects on the host. In addition to the previously mentioned SCFAs, the gut microflora thus generates many important bioactive metabolites.

\section{Polyphenols}

A vegetarian diet is abundant in polyphenols and antioxidants, which are secondary plant metabolites with many important properties such as anti-inflammatory, antimicrobial, antiradical and anticancer activity [99, 100]. It has also been shown that anthocyanins, important compounds present in various types of berries, can promote urinary tract and dermal health, as well as exhibiting anticancer, antioxidant, neuroprotective, cardioprotective and antidiabetic properties [101, 102]. The bioavailability and impact 


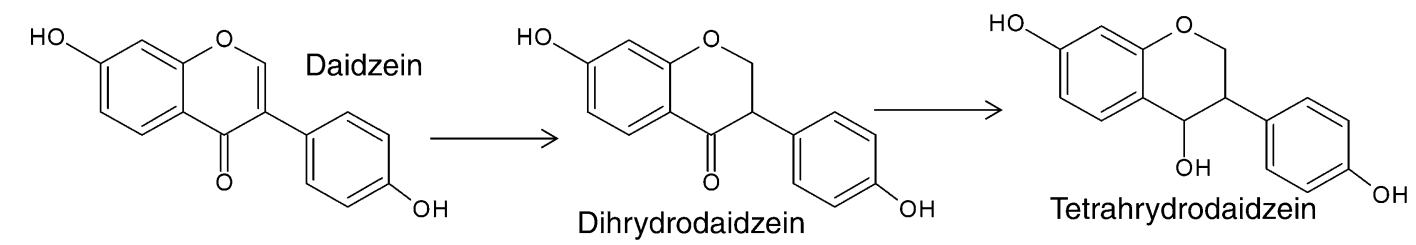

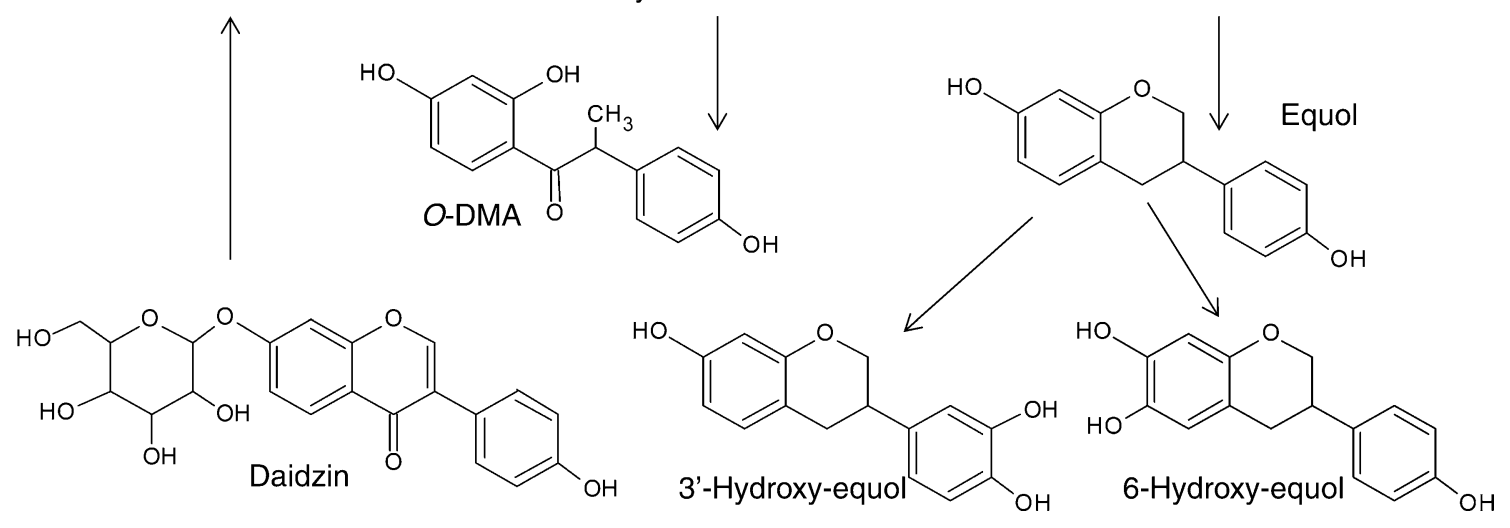

Fig. 1 Proposed pathways of bacterial metabolism of daidzin and daidzein (based on [16, 103, 111]) (color figure online)

of polyphenols on the host greatly depend on their transformation by specific components of the gut microbiota via esterase, glucosidase, demethylation, dehydroxylation and decarboxylation activities [97].

Owing to the great diversity of species forming the intestinal microbiota in different individuals, the profile of polyphenol metabolites that are generated and their final effect on the body are highly variable within the human population. In many situations, only a product of bacterial metabolism of a polyphenol can be absorbed and exert a beneficial impact in humans. A lack of particular species within the microbiota may mean that a polyphenol cannot exert its expected effect even though it has been consumed.

One of the better-characterized types of polyphenol metabolites are the nonsteroidal estrogens. Some intestinal bacteria, such as Eggerthella spp. strain YY7918, Eggerthella spp. Julong 732, Enterococcus faecium, Adlercreutzia equolifaciens, Slackia equolifaciens, Lactobacillus mucosae, Bifidobacterium spp., Slackia isoflavoniconvertens and Bacteroides ovatus [103-109], are able to metabolize the soya isoflavone daidzein to equol and/ or O-desmethylangolensin (O-DMA). The prevalence of equol producers and O-DMA producers is approximately $30-50$ and $80-90 \%$, respectively [108-110], and the rate of equol formation is influenced by dietary habits, food matrix, composition of the intestinal microflora, extent of intestinal bacterial fermentation, intestinal transit time and alterations in the redox level in the large intestine [111]. The metabolic pathways of daidzein degradation by bacteria are presented in Fig. 1.

Equol exerts many different effects, the most important being endocrine. Its high binding affinity to the estrogen receptor (S-equol preferentially activates ER $\beta$ ) [108, 109, 112] has been used to alleviate the symptoms of menopause [107]. Antiandrogenic effects and inhibition of osteoclast formation have also been observed [113-115]. In vitro studies have revealed anticancer activities, mainly due to the inhibition of cancer cell migration and invasion, as well as induction of apoptosis in cancer cells [116, 117]. Antiinflammatory effects are the results of iNOS inhibition and eNOS activation [118]. Other ligands for estrogen receptors are enterolactone, enterodiol, urolithin A and 8-prenylnaringenin. These are polyphenol metabolites generated by various bacteria, e.g., Bacteroides spp., Clostridium spp., Eubacterium limosum and E. lenta [119-121]. Enterolactone and enterodiol are lignan derivatives of polyphenols from sesame seed or flaxseed, urolithin A is a metabolite of ellagitannins from various berries, while 8-prenylnaringenin is generated from isoxanthohumol present in hops (Fig. 2). All of these can bind to estrogen receptors and inhibit cancer development by the inhibition of cancer proliferation, invasion and angiogenesis [121-123].

Some polyphenols and products of their metabolism have a negative effect. For example, owing to metabolism by intestinal bacteria, quercetin and rutin can be transformed to 3,4-dihydrophenylacetic acid (DOPAC) (Fig. 3), which is a metabolite of the neurotransmitter dopamine. It has been demonstrated that DOPAC has anticancer, antiinflammatory, cardioprotective and neuroprotective properties. However, in the presence of the NO radical, DOPAC inhibits mitochondrial respiration in isolated brain mitochondria, leading to mitochondrial dysfunction, which might be an important mechanism involved in the neurodegeneration associated with Parkinson's disease [124-126]. 
a

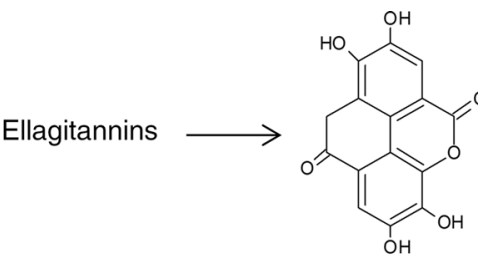

Ellagic acid

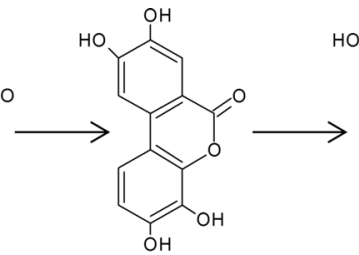

Urolithin D<smiles>O=C1C=C2OC(=O)c3cc(O)c(O)cc3C=C2OCCc2ccc(O)c(c2)-c2ccc(O)cc2O1</smiles>

Urolithin C

Urolithin A b<smiles>COc1cc(O)c(CC=C(C)C)c2c1C(=O)C[C@@H](c1ccc(O)cc1)O2</smiles>

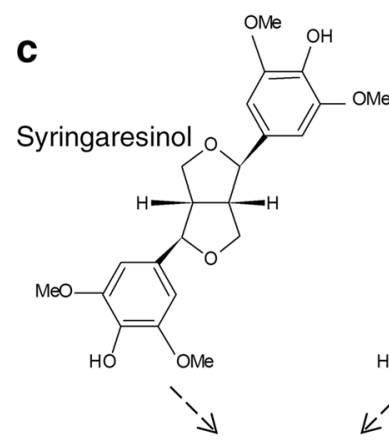

Secoisolariciresinol

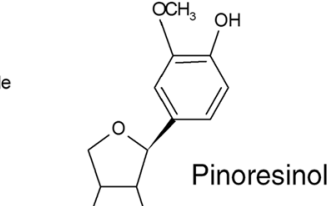<smiles>COc1cc(CC2COC(=O)C2Cc2ccc(O)c(OC)c2)ccc1O</smiles>

Sesaminol

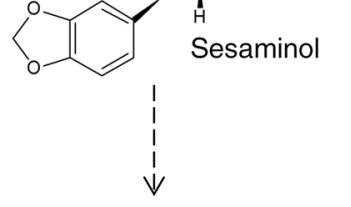

Matairesinol
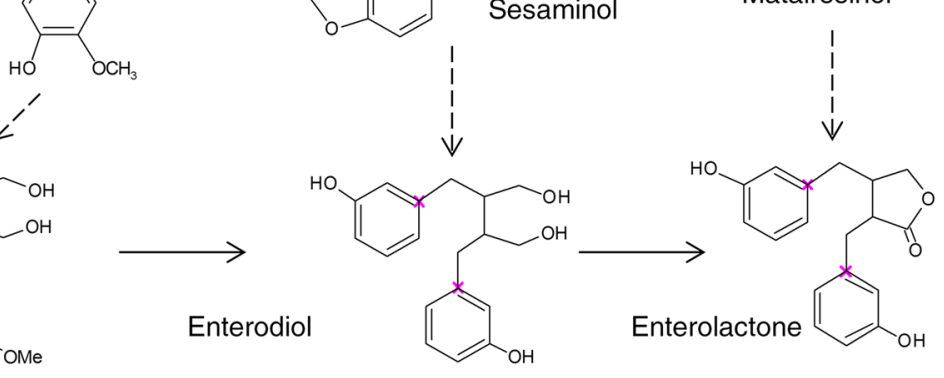

Enterodiol

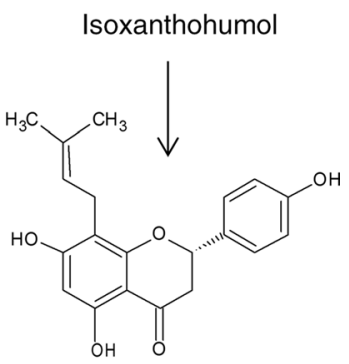

8-Prenylnaringenin

Fig. 2 Ligands for estrogen receptors generated by the intestinal microbiota: a urolithin A; b 8-prenylnaringenin; and $\mathbf{c}$ enterolactone and enterodiol (based on 16, 97, 120) (color figure online)

Procyanidins, oligomers of flavan-3-ols, are present in many fruits, especially in berries, wine, tea and nuts. They can be metabolized by intestinal bacteria to 3,4-dihydroxyphenylvaleric acid, which can be further degraded into phenolic acids such as 3,4-dihydroxyphenylpropionic (dihydrocaffeic acid) and 3,4-benzoic acids. However, recent studies have postulated that $\alpha$-oxidation of 3,4-dihydroxyphenylvaleric acid can lead to 3,4-dihydroxyphenylacetic acid formation, which means that this compound can be released from both monomeric and dimeric flavonols (procyanidin) [127].

Excessive intake of many polyphenolic compounds seems to exert an adverse effect on the body [128]. First of all, in the presence of $\mathrm{O}_{2}$ and transition metals $(\mathrm{Cu}, \mathrm{Fe})$, some polyphenols may act as pro-oxidants, leading to damage of DNA, lipids and other biological molecules. This pro-oxidant activity can be applied for cancer therapy and has a beneficial impact on the host cell, but if uncontrolled, the effect will be detrimental. Moreover, flavonoids can change the activity of phase I and II metabolizing enzymes, such as cytochrome P450 (CYP), P-form phenol sulfotransferase, glutathione S-transferase, $\mathrm{NAD}(\mathrm{P}) \mathrm{H}$ :quinone oxidoreductase and UDP-glucuronyl transferase. This inhibitory/stimulatory activity of particular polyphenols is utilized in cancer therapy [128]. However, it has been observed that simultaneous administration of flavonoids and clinically used drugs may cause flavonoid-drug interactions. Such interactions, by modulating the pharmacokinetics of the drugs, can increase their toxicity or diminish their therapeutic effect, depending on the flavonoid structure [128]. Naringenin, a major flavanone present in grapefruit juice, exerts an inhibitory effect on intestinal CYP3A4 within $30 \mathrm{~min}$. This means that the metabolism of certain drugs, such as those belonging to calcium channel antagonist or immunosuppressant groups (e.g., felodipine, nitrendipine, nicardipine, amlodipine, nisoldipine, verapamil, terfenadine, cyclosporine, midazolam, triazolam), would be impaired if they were co-administered with grapefruit juice [129].

The bioactive properties of polyphenol metabolites can be completely different from the activity of the parent compounds. There are approximately 700 anthocyanins isolated from plants, but the most commonly known are based on six anthocyanidins: cyanidin, delphinidin, pelargonidin, peonidin, petunidin and malvidin $[130,131]$. The majority of dietary anthocyanins are not absorbed in the upper parts of the gastrointestinal tract, so they reach the colon and are metabolized by intestinal microbiota, resulting in the generation of new compounds, which may be absorbed and thus have an impact on both the microbiota and the host. The 


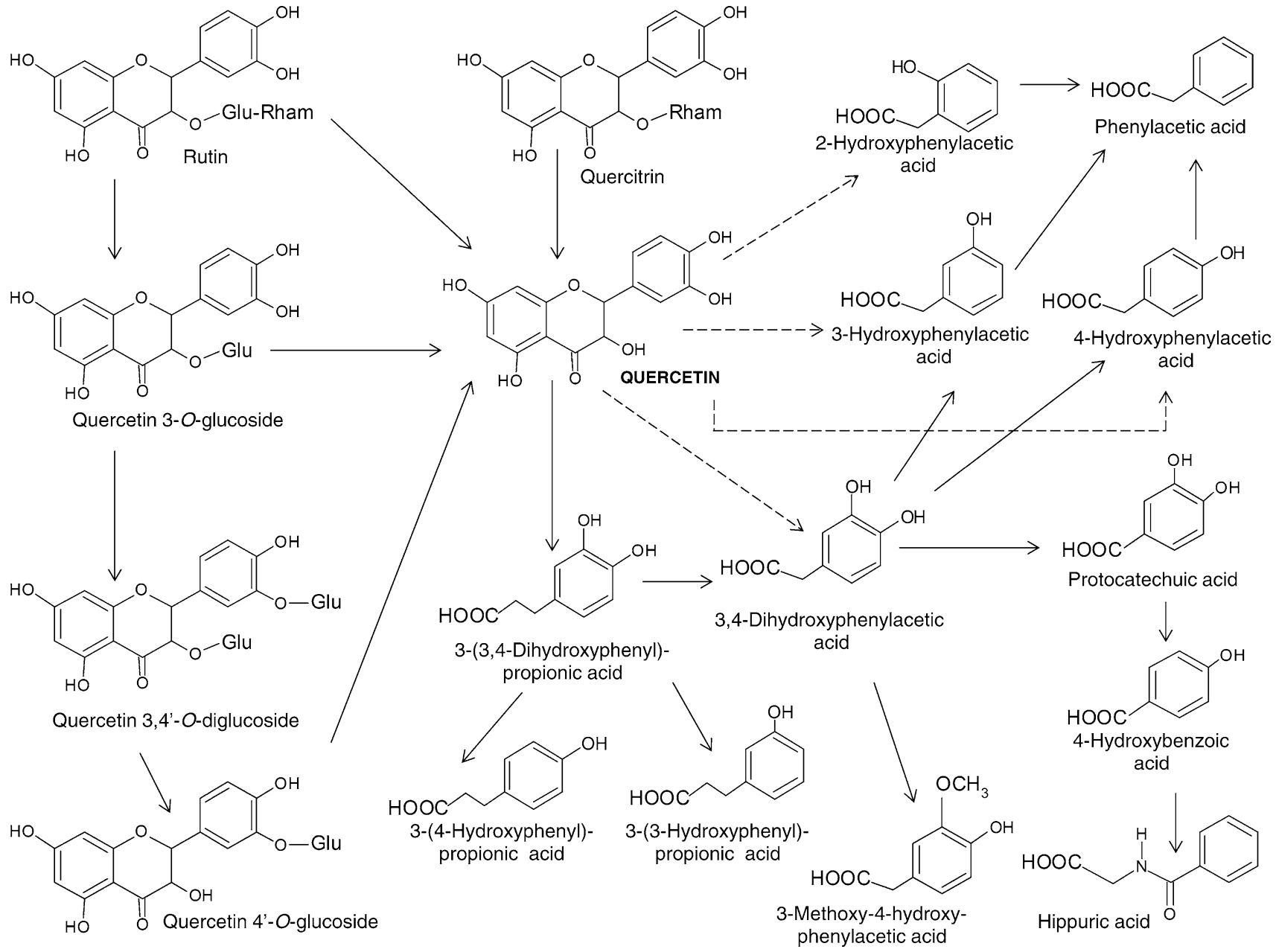

Fig. 3 Possible pathways of the transformation of quercetin and its glycosides due to metabolism by intestinal bacteria (based on [16, 138, 156, 157]) (color figure online)

bacterial catabolism of anthocyanins involves the cleavage of 3-glycosidic linkages by bacterial $\beta$-glucosidase, which causes instability of the anthocyanidin at neutral $\mathrm{pH}$ and rapid breakdown of the heterocyclic ring. The major stable products of degradation are corresponding phenolic acids (derived from the B-ring of the anthocyanin skeleton) and phloroglucinol derivatives (from A-ring) [131, 132].

The main phenolic acids found as the colonic metabolites of various anthocyanins are protocatechuic, gallic, syringic, $p$-coumaric and vanillic acids [131]. The other products of anthocyanin degradation by intestinal microbiota are 2,4-dihydroxybenzoic acid and 2,4,6-trihydroxybenzoic acid, which have been detected in in vitro studies [133].

Protocatechuic acid (PCA) is one of the main bacterial metabolites of complex polyphenols such as anthocyanins and procyanidins that are normally found at high concentrations in vegetables and fruit [134]. Available results support the concept that PCA can exert a variety of biological effects by acting on different molecular targets. It has been shown that PCA possesses antioxidant, anti-inflammatory, antihyperglycemic and neuroprotective activities and may thus have a preventative role in various diseases. Moreover, it inhibits in vitro carcinogenesis and exerts proapoptotic and antiproliferative effects in different tissues [135], inhibits monocyte adhesion to tumor necrosis factor-alpha-activated mouse aortic endothelium, exerts an antiatherogenic effect and decreases cholesterol levels [136-139]. The anthocyanin microbial catabolites, such as gallic acid, 3-O-methyl-gallic acid and 2,4,6-trihydroxybenzaldehyde, have been tested for their ability to induce apoptosis and inhibit cell proliferation in a colon cancer model using Caco- 2 cells. All of these compounds reduced cell proliferation without being cytotoxic and were more effective than the parent anthocyanins [140]. Other anthocyanin degradation products, $3^{\prime}$-hydroxyphenylacetic acid, $3^{\prime}, 4^{\prime}$-dihydroxyphenylacetic acid and $3^{\prime}$-methoxy$4^{\prime}$-hydroxyphenylacetic acid, inhibited the formation of 
advanced glycation end-products and were effective in preserving cultivated neuron cells from death due to oxidative stress [141].

Anaerobic bacteria such as Bacteroides distasonis, $B$. uniformis and $B$. ovatus can release aglycone from quercetin glycosides owing to their $\beta$-glucosidase activity [138]. Enterobacteria also decompose quercetin aglycone to produce its ring scission products such as 3,4-dihydroxyphenylacetic acid, m-hydroxyphenylacetic acid and $\mathrm{m}$-homovanillic acid [139]. The aglycone is converted to its conjugated metabolites with or without O-methylation and then transferred to the liver through the portal vein. Some conjugated metabolites are likely to be transferred into the systemic circulation via lymph. Quercetin glucuronides are another kind of quercetin metabolite in humans, and their plasma concentration as well as biological activity depends on the conjugation position. Day et al. [142] demonstrated that the 5-position did not appear to be a site for quercetin conjugation. The K(i) for the inhibition of xanthine oxidase by quercetin glucuronides followed the order $4^{\prime}->3^{\prime}->7->3-$, with quercetin-4'-glucuronide a particularly potent inhibitor. The glucuronides, with the exception of quercetin-3-glucuronide, were also inhibitors of lipoxygenase. It was demonstrated that quercetin metabolites are likely to exert their physiological function at the target sites where they concentrate. It is highly probable that conjugated metabolites of quercetin circulate as nontoxic forms in the bloodstream, but are later converted to active aglycones to exert their function immediately. This effect was observed by Kawai et al. [143]. In vitro experiments using murine macrophage cell lines showed that quercetin-3-glucuronide (Q3GA) was taken up in significant quantities and deconjugated into the much more active aglycone, a part of which was further converted to the methylated form, in activated macrophages. Q3GA accumulated only in atherosclerotic lesions but not in normal aorta [143].

\section{Vitamins}

The microbiota is involved in the production and absorption of essential vitamins and micronutrients. The increased concentration of SCFAs, which is a final result of bacteria's metabolism of resistant starch and oligosaccharide, may help in the absorption of minerals such as calcium, by increasing their solubility and increasing the expression of calcium binding proteins [144]. Many studies have shown that resistant carbohydrate can be utilized by the intestinal bacteria for folate biosynthesis. The main producers of folate are Bifidobacterium bifidum and B. longum subsp. infantis [145], Lactococcus lactis subsp. lactis, Streptococcus thermophilus [146], B. adolescentis, B. pseudocatenulatum [147] and L. plantarum [148]. A number of other B-group vitamins are synthesized by members of the gut microbiota, such as thiamine, riboflavin, niacin, pantothenic acid, pyridoxine, biotin and vitamin B12 [145, 149]. There are also some studies that indicate a role of the intestinal microbiota in menaquinone (vitamin K2) production in the human gastrointestinal tract. Major vitamin $\mathrm{K}$ producers are species from the Bacteroides genus, E. coli, as well as some strains of $K$. pneumoniae, Propionibacterium and Eubacterium species [150]. A negative correlation between a low-fiber diet and the abundance of menaquinone-producing bacteria in the gut has been demonstrated [151].

Among other important bioactive compounds produced by the intestinal microbiota are bacteriocins, factors that inhibit the growth of pathogenic bacteria. Bacteriocin-producing strains of the Pediococcus and Lactococcus genera have been isolated from human intestine [152]. It has also been shown that human isolates of Pediococcus acidilact$i c i$-producing pediocin PA-1 and L. lactis-producing nisin $\mathrm{Z}$ are able to reduce intestinal colonization by vancomycinresistant enterococci in a mouse model [153]. Moreover, $L$. lactis and P. acidilactici administration increased the total number of lactic acid bacteria and anaerobes, while $P$. acidilactici decreased the Enterobacteriaceae population.

\section{Conclusions}

For many years, the perception of the function of the large intestine was that it was limited to the reabsorption of water and salt and the removal of unused food debris, completely ignoring the microbiota present. Currently, it is known that a large number of bacteria inhabiting the large intestine form a very complex ecosystem called the 'intestinal microbiome'. The intestinal microbiome plays an important, possibly crucial, role in the metabolism of chemical compounds found in foods. It is estimated that its metabolic capacity is approximately 100 -fold greater than the capacity of the liver, because of the great diversity of bacterial species forming the population, and hence the large number of genes that they contain [4]. Moreover, the enormous total number of microorganisms that inhabit the large intestine has considerable influence. There are approximately $10^{12}$ bacteria per gram of colonic content, which is the highest accumulation of microorganisms that has ever been noted in any environment [13].

Owing to the multitude of direct and indirect interactions with the host organism, the intestinal microbiome is closely linked to the health of the host [15]. The microbiota plays a protective role by occupying intestinal surfaces and creating a milieu that prevents the invasion of pathogens (e.g., by production of bacteriocins and other antimicrobial compounds). Moreover, the metabolism of those bacteria enables the breakdown of indigestible compounds 
such as resistant starch and plant polysaccharides during anaerobic fermentation, which results in SCFA production. Other examples of bacterial metabolism are vitamin and amino acid synthesis [14]. These metabolites can then serve as growth signals and nourishment for the intestinal epithelium of the host, as well as for other microorganisms. Furthermore, the etiology of many diseases is largely correlated with the intestinal microbiome or certain microbial members. A balance between the host immune system and the commensal gut microbiota is crucial for maintaining health. If this balance is disturbed (dysbiosis), the host-microbe relationship can progress toward a disease state [14, 25]. Recent studies suggest that specific members of the gut microbiota play a functional role in inflammatory bowel disease (including Crohn's disease), colorectal cancers, obesity and allergies $[4,14,15,22,28$, 97, 154, 155].

Over the course of evolution, the human organism has developed tools indispensable for the utilization of sugars, lipids and proteins. Despite this, many of these compounds enter further segments of the gastrointestinal tract undigested (intact), where they interact with the intestinal microbiota. Bacteria use these compounds as a source of energy and nutrients via their own enzymes, some of which cannot be produced by human tissues. It should be remembered that many of these substances have antibacterial properties. This enables the elimination of pathogens, but may have also a detrimental effect due to elimination of beneficial microflora. Typically, xenobiotics undergo biotransformation processes via the intestinal bacteria, which are necessary for their detoxification. The potential of the intestinal microbiome for detoxification or bioactivation of xenobiotics is much higher than that of the liver and includes other types of reactions not found in the liver. Hepatic metabolism is based on the reactions of oxidation and conjugation, mainly resulting in the generation of hydrophilic high molecular weight metabolites. Bacterial metabolism occurs under anaerobic conditions and is based mainly on reduction and hydrolysis reactions, resulting in nonpolar low molecular weight products. Therefore, bacterial metabolites are different from those that can be generated by human enzymes, and their impact on both host health and intestinal microbiota thus differs.

Bacterial metabolism usually reduces the activity of dietary compounds such as polyphenols, but sometimes a specific product of bacterial transformation exhibits enhanced properties. The products of bacterial metabolism may exhibit enhanced or more beneficial effects, or they may be degraded to inactive or toxic compounds. Studies on the metabolism of polyphenols by the intestinal microbiota are therefore crucial for understanding the role of these compounds and their effects on our health.
Acknowledgments This paper has been financially supported by grants (Decision Number DEC-2011/01/B/NZ9/00226 and DEC2011/01/B/NZ9/00218) from the National Science Centre (NCN, Poland).

Conflict of interest On behalf of all authors, the corresponding author states that there is no conflict of interest.

Open Access This article is distributed under the terms of the Creative Commons Attribution License which permits any use, distribution, and reproduction in any medium, provided the original author(s) and the source are credited.

\section{References}

1. Hooper LV, Gordon JI (2001) Commensal host-bacterial relationships in the gut. Science 292:1115-1118. doi:10.1126/ science. 1058709

2. O'Hara AM, Shanahan F (2006) The gut flora as a forgotten organ. EMBO Rep 7(7):688-693. doi:10.1038/ sj.embor.7400731

3. Hattori M, Taylor TD (2009) The human intestinal microbiome: a new frontier of human biology. DNA Res 16:1-12. doi:10.1093/dnares/dsn033

4. Zhu B, Wang X, Li L (2010) Human gut microbiome: the second genome of human body. Protein Cell 1(8):718-725. doi:10.1007/s13238-010-0093-z

5. Sakata H, Yoshioka H, Fujita K (1985) Development of the intestinal flora in very low birth weight infants compared to normal full-term newborns. Eur J Pediatr 144:186-190. doi:10.1203/01.PDR.0000078274.74607.7A

6. Fanaro S, Chierici R, Guerrini P, Vigi V (2003) Intestinal microflora in early infancy: composition and development. Acta Paediatr Suppl 441:48-55. doi:10.1111/j.1651-2227.2003. tb00646.x

7. Penders J, Thijs C, Vink C, Stelma FF, Snijders B, Kummeling I, van den Brandt PA, Stobberingh EE (2006) Factors influencing the composition of the intestinal microbiota in early infancy. Pediatrics 118(2):511-521. doi:10.1542/peds.2005-2824

8. Zoetendal EG, Akkermans AD, De Vos WM (1998) Temperature gradient gel electrophoresis analysis of $16 \mathrm{~S}$ rRNA from human fecal samples reveals stable and host-specific communities of active bacteria. Appl Environ Microbiol 64(10):3854-3859

9. Brown K, DeCoffe D, Molcan E, Gibson DL (2012) Dietinduced dysbiosis of the intestinal microbiota and the effects on immunity and disease. Nutrients 4(8):1095-1119. doi:10.3390/ nu4081095

10. Salminen S, Gibson GR, McCartney AL, Isolauri E (2004) Influence of mode of delivery on gut microbiota composition in seven year old children. Gut 53(9):1388-1389. doi:10.1136/ gut.2004.041640

11. Dominguez-Bello MG, Costello EK, Contreras M, Magris M, Hidalgo G, Fierer N, Knight R (2010) Delivery mode shapes the acquisition and structure of the initial microbiota across multiple body habitats in newborns. Proc Natl Acad Sci USA 107(26):11971-11975. doi:10.1073/pnas.1002601107

12. Hakansson A, Molin G (2011) Gut microbiota and inflammation. Nutrients 3(6):637-682. doi:10.3390/nu3060637

13. Whitman WB, Coleman DC, Wiebe WJ (1998) Prokaryotes: the unseen majority. Proc Natl Acad Sci USA 95:6578-6583. doi:10.1073/pnas.95.12.6578 
14. Dicksved J (2008) Exploring the human intestinal microbiome in health and disease. Dissertation, Thesis Swedish University of Agricultural Sciences, Acta Universitatis Agriculturae Sueciae 2008:30. Uppsala. http://pub.epsilon.slu.se/1760/1/ Dicksved_Thesis_Kappan.pdf Accessed 24 Apr 2014

15. Saarela $\mathrm{M}$, Lähteenmäki L, Crittenden R, Salminen S, MattilaSandholm T (2002) Gut bacteria and health foods-the European perspective. Int J Food Microbiol 78:99-117. doi:10.1016/ S0168-1605(02)00235-0

16. Del Rio D, Rodriguez-Mateos A, Spencer JPE, Tognolini M, Borges G, Crozier A (2013) Dietary (poly) phenolics in human health: structures, bioavailability, and evidence of protective effects against chronic diseases. Antioxid Redox Signal 18(14):1818-1892. doi:10.1089/ars.2012.4581

17. Eckburg PB, Bik EM, Bernstein CN, Purdom E, Dethlefsen L, Sargent M, Gill SR, Nelson KE, Relman DA (2005) Diversity of the human intestinal microbial flora. Science 308(5728):16351638. doi:10.1126/science. 1110591

18. Andersson AF, Lindberg M, Jakobsson H, Bäckhed F, Nyrén P, Engstrand L (2008) Comparative analysis of human gut microbiota by barcoded pyrosequencing. PLoS ONE 3(7):e2836. doi:10.1371/journal.pone.0022109

19. Lagier JC, Million M, Hugon P, Armougom F, Raoult D (2012) Human gut microbiota: repertoire and variations. Front Cell Infect Microbiol 2:136. doi:10.3389/fcimb.2012.00136http:// www.ncbi.nlm.nih.gov/pmc/articles/PMC3487222/ Accessed 19 Dec 2014

20. Qin J, Li R, Raes J, Arumugam M, Burgdorf KS, Manichanh C, Nielsen T, Pons N, Levenez F, Yamada T, Mende DR, Li J, Xu J, Li S, Li D, Cao J, Wang B, Liang H, Zheng H, Xie Y, Tap J, Lepage P, Bertalan M, Batto JM, Hansen T, Le Paslier D, Linneberg A, Nielsen HB, Pelletier E, Renault P, SicheritzPonten T, Turner K, Zhu H, Yu C, Li S, Jian M, Zhou Y, Li Y, Zhang X, Li S, Qin N, Yang H, Wang J, Brunak S, Doré J, Guarner F, Kristiansen K, Pedersen O, Parkhill J, Weissenbach J, MetaHIT Consortium, Bork P, Ehrlich SD, Wang J (2010) A human gut microbial gene catalogue established by metagenomic sequencing. Nature 464(7285):59-65. doi:10.1038/ nature 08821

21. Matsuki T, Watanabe K, Fujimoto J, Takada T, Tanaka R (2004) Use of $16 \mathrm{~S}$ rRNA gene-targeted group-specific primers for Real-Time PCR analysis of predominant bacteria in human feces. Appl Environ Microbiol 70(12):7220-7228. doi:10.1128/ AEM.70.12.7220-7228.2004

22. Frank DN, St Amand AL, Feldman RA, Boedeker EC, Harpaz N, Pace NR (2007) Molecular-phylogenetic characterization of microbial community imbalances in human inflammatory bowel diseases. Proc Natl Acad Sci USA 104:13780-13785. doi:10.1073/pnas.0706625104

23. Hayashi H, Takahashi R, Nishi T, Sakamoto M, Benno Y (2005) Molecular analysis of jejunal, ileal, caecal and recto-sigmoidal human colonic microbiota using 16S rRNA gene libraries and terminal restriction fragment length polymorphism. J Med Microbiol 54(Pt 11):1093-1101. doi:10.1099/jmm.0.45935-0

24. Wang M, Ahrné S, Jeppsson B, Molin G (2005) Comparison of bacterial diversity along the human intestinal tract by direct cloning and sequencing of 16S rRNA genes. FEMS Microbiol Ecol 54(2):219-231. doi:10.1016/j.femsec.2005.03.012

25. Jeffery IB, O'Toole PW (2013) Diet-microbiota interactions and their implications for healthy living. Nutrients 5(1):234 252. doi: $10.3390 /$ nu5010234

26. Mariat D, Firmesse O, Levenez F, Guimarăes V, Sokol H, Doré J, Corthier G, Furet JP (2009) The Firmicutes/Bacteroidetes ratio of the human microbiota changes with age. BMC Microbiol 9:123. doi:10.1186/1471-2180-9-123. http://www.biomedcentral.com/1471-2180/9/123. Accessed 12 Apr 2014
27. Agans A, Rigsbee L, Kenche H, Michail S, Khamis HJ, Paliy O (2011) Distal gut microbiota of adolescent children is different from that of adults. FEMS Microbiol Ecol 77:404-412. doi:10.1111/j.1574-6941.2011.01120.x

28. Ley RE, Turnbaugh PJ, Klein S, Gordon JI (2006) Microbial ecology: human gut microbes associated with obesity. Nature 444(7122):1022-1023. doi:10.1038/4441022a

29. De Filippo C, Cavalieri D, Di Paola M, Ramazzotti M, Poullet JB, Massart S, Collini S, Pieraccini G, Lionetti P (2011) Impact of diet in shaping gut microbiota revealed by a comparative study in children from Europe and rural Africa. Proc Natl Acad Sci U S A 107(33):14691-14696. doi:10.1073/ pnas. 1005963107

30. Laparra JM, Sanz Y (2010) Interactions of gut microbiota with functional food components and nutraceuticals. Pharmacol Res 61(3):219-225. doi:10.1016/j.phrs.2009.11.001

31. Duda-Chodak A (2012) The inhibitory effect of polyphenols on human gut microbiota. J Physiol Pharmacol 63(5):497-503

32. Collado MC, Calabuig M, Sanz Y (2007) Differences between the fecal microbiota of coeliac infants and healthy controls. Curr Issues Intest Microbiol 8(1):9-14

33. Sanz Y (2010) Effects of a gluten-free diet on gut microbiota and immune function in healthy adult humans. Gut Microbes 1(3):135-137. doi:10.4161/gmic.1.3.11868

34. Gibson GR (2008) Prebiotics as gut microflora management tools. J Clin Gastroenterol 42(Suppl 2):S75-S79. doi:10.1097/ MCG.0b013e31815ed097

35. Moshfegh AJ, Friday JE, Goldman JP, Ahuja JK (1999) Presence of inulin and oligofructose in the diets of Americans. $\mathbf{J}$ Nutr 129(7 Suppl):1407S-1411S

36. Rigon G, Vallone C, Lucantoni V, Signore F (2012) Maternal factors pre- and during delivery contribute to gut microbiota shaping in newborns. Front Cell Infect Microbiol 2:93. doi:10.3389/fcimb.2012.00093. http://www.ncbi.nlm.nih.gov/ pmc/articles/PMC3417649/ Accessed 24 Apr 2014

37. Hehemann JH, Correc G, Barbeyron T, Helbert W, Czjzek M, Michel G (2010) Transfer of carbohydrate-active enzymes from marine bacteria to Japanese gut microbiota. Nature 464(7290):908-912. doi:10.1038/nature08937

38. Kurokawa K, Itoh T, Kuwahara T, Oshima K, Toh H, Toyoda A, Takami H, Morita H, Sharma VK, Srivastava TP, Taylor TD, Noguchi H, Mori H, Ogura Y, Ehrlich DS, Itoh K, Takagi T, Sakaki Y, Hayashi T, Hattori M (2007) Comparative metagenomics revealed commonly enriched gene sets in human gut microbiomes. DNA Res 14(4):169-181. doi:10.1093/dnares/ dsm018

39. Hildebrandt MA, Hoffmann C, Sherrill-Mix SA, Keilbaugh SA, Hamady M, Chen YY, Knight R, Ahima RS, Bushman F, Wu GD (2009) High-fat diet determines the composition of the murine gut microbiome independently of obesity. Gastroenterology 137(5):1716-1724. doi:10.1053/j.gastro.2009.08.042

40. Turnbaugh PJ, Ridaura VK, Faith JJ, Rey FE, Knight R, Gordon JI (2009) The effect of diet on the human gut microbiome: a metagenomic analysis in humanized gnotobiotic mice. Sci Transl Med 1(6):6ra14. doi:10.1126/scitranslmed.3000322

41. Wu GD, Chen J, Hoffmann C, Bittinger K, Chen YY, Keilbaugh SA, Bewtra M, Knights D, Walters WA, Knight R, Sinha R, Gilroy E, Gupta K, Baldassano R, Nessel L, Li H, Bushman FD, Lewis JD (2011) Linking long-term dietary patterns with gut microbial enterotypes. Science 334(6052):105-108. doi:10.1126/science.1208344

42. Santacruz A, Marcos A, Wärnberg J, Martí A, Martin-Matillas M, Campoy C, Moreno LA, Veiga O, Redondo-Figuero C, Garagorri JM, Azcona C, Delgado M, García-Fuentes M, Collado MC, Sanz Y; EVASYON Study Group (2009) Interplay between weight loss and gut microbiota composition in 
overweight adolescents. Obesity (Silver Spring) 17(10):19061915. doi:10.1038/oby.2009.112

43. Ismail NA, Ragab SH, ElBaky AA, Shoeib ARS, Alhosary Y, Fekry D (2011) Frequency of Firmicutes and Bacteroidetes in gut microbiota in obese and normal weight Egyptian children and adults. Arch Med Sci 7(3):501-507. doi:10.5114/ aoms.2011.23418

44. Green CJ (2001) Fibre in enteral nutrition. Clin Nutr 20(Suppl. 1):23-39. doi:10.1054/clnu.2001.0425

45. Zimmer J, Lange B, Frick JS, Sauer H, Zimmermann K, Schwiertz A, Rusch K, Klosterhalfen S, Enck P (2012) A vegan or vegetarian diet substantially alters the human colonic faecal microbiota. Eur J Clin Nutr 66:53-60. doi:10.1038/ ejen.2011.141

46. Peterson J, Dwyer J, Bhagwat S, Haytowit D, Holden J, Eldridge AL, Beecher G, Aladesanmi J (2005) Major flavonoids in dry tea. J Food Compost Anal 18:487-501. doi:10.1016/j. jfca.2004.05.006

47. Ankolekar C, Johnson D, Pinto Mda S, Johnson K, Labbe R, Shetty K (2011) Inhibitory potential of tea polyphenolics and influence of extraction time against Helicobacter pylori and lack of inhibition of beneficial lactic acid bacteria. J Med Food 14(11):1321-1329. doi:10.1089/jmf.2010.0237

48. Shin JS, Chung HS (2007) Antibacterial activities of phenolic components from Camellia sinensis $\mathrm{L}$. on pathogenic microorganisms. J Food Sci Nutr 12:135-140. doi:10.3746/ jfn.2007.12.3.135

49. Nakayama M, Shigemune N, Tsugukuni T, Jun H, Matsushita T, Mekada Y, Kurahachi M, Miyamoto T (2012) Mechanism of the combined anti-bacterial effect of green tea extract and $\mathrm{NaCl}$ against Staphylococcus aureus and Escherichia coli O157:H7. Food Control 25(1):225-232. doi:10.1016/j. foodcont.2011.10.021

50. Kohda C, Yanagawa Y, Shimamura T (2008) Epigallocatechin gallate inhibits intracellular survival of Listeria monocytogenes in macrophages. Biochem Biophys Res Commun 365(2):310 315. doi:10.1016/j.bbrc.2007.10.190

51. Si W, Gong J, Tsao R, Kalab M, Yang R, Yin Y (2006) Bioassay-guided purification and identification of antimicrobial components in Chinese green tea extract. J Chromatogr A 1125(2):204-210. doi:10.1016/j.chroma.2006.05.061

52. Bancirova M (2010) Comparison of the antioxidant capacity and the antimicrobial activity of black and green tea. Food Res Int 43:1379-1382. doi:10.1016/j.foodres.2010.04.020

53. Chen YL, Tsai HL, Peng CW (2012) EGCG debilitates the persistence of EBV latency by reducing the DNA binding potency of nuclear antigen 1. Biochem Biophys Res Commun 417(3):1093-1099. doi:10.1016/j.bbrc.2011.12.104

54. Nakayama M, Suzuki K, Toda M, Okubo S, Hara Y, Shimamura $\mathrm{T}$ (1993) Inhibition of the infectivity of influenza virus by tea polyphenols. Antiviral Res 21(4):289-299

55. Liu S, Lu H, Zhao Q, He Y, Niu J, Debnath AK, Wu S, Jiang $S$ (2005) Theaflavin derivatives in black tea and catechin derivatives in green tea inhibit HIV-1 entry by targeting gp41. Biochim Biophys Acta 1723(1-3):270-281. doi:10.1016/j. bbagen.2005.02.012

56. Hamza A, Zhan CG (2006) How can (-)-epigallocatechin gallate from green tea prevent HIV-1 infection? Mechanistic insights from computational modeling and the implication for rational design of anti-HIV-1 entry inhibitors. J Phys Chem B 110(6):2910-2917. doi:10.1021/jp0550762

57. Williamson MP, McCormick TG, Nance CL, Shearer WT (2006) Epigallocatechin gallate, the main polyphenol in green tea, binds to the T-cell receptor, CD4: potential for HIV-1 therapy. J Allergy Clin Immunol 118(6):1369-1374. doi:10.1016/j. jaci.2006.08.016
58. Park BJ, Park JC, Taguchi H, Fukushima K, Hyon SH, Takatori K (2006) Antifungal susceptibility of epigallocatechin 3-O-gallate $(\mathrm{EGCg})$ on clinical isolates of pathogenic yeasts. Biochem Biophys Res Commun 347(2):401-405. doi:10.1016/j. bbrc.2006.06.037

59. Lee HC, Jenner AM, Low CS, Lee YK (2006) Effect of tea phenolics and their aromatic fecal bacterial metabolites on intestinal microbiota. Res Microbiol 157(9):876-984. doi:10.1016/j. resmic.2006.07.004

60. Bae EA, Han MJ, Kim DH (1999) In vitro anti-Helicobacter pylori activity of some flavonoids and their metabolites. Planta Med 65(5):442-443. doi:10.1055/s-2006-960805

61. Parkar SG, Stevenson DE, Skinner MA (2008) The potential influence of fruit polyphenols on colonic microflora and human gut health. Int J Food Microbiol 124(3):295-298. doi:10.1016/j. ijfoodmicro.2008.03.017

62. Rodríguez Vaquero MJ, Alberto MR, Manca de Nadra MC (2007) Antibacterial effect of phenolic compounds from different wines. Food Control 18:93-101. doi:10.1111/j.1745-4514.2011.00648.x

63. Tzounis X, Vulevic J, Kuhnle GG, George T, Leonczak J, Gibson GR, Kwik-Uribe C, Spencer JP (2008) Flavanol monomerinduced changes to the human faecal microflora. $\mathrm{Br} \mathrm{J}$ Nutr 99(4):782-792. doi:10.1017/S0007114507853384

64. Smith AH, Zoetendal E, Mackie RI (2005) Bacterial mechanisms to overcome inhibitory effects of dietary tannins. Microb Ecol 50:197-205. doi:10.1007/s00248-004-0180-x

65. Dolara P, Luceri C, De Filippo C, Femia AP, Giovannelli L, Caderni G, Cecchini C, Silvi S, Orpianesi C, Cresci A (2005) Red wine polyphenols influence carcinogenesis, intestinal microflora, oxidative damage and gene expression profiles of colonic mucosa in F344 rats. Mutat Res 591(1-2):237-246. doi:10.1016/j.mrfmmm.2005.04.022

66. Sanchez-Patan F, Cueva C, Monagas M, Walton GE, Gibson GR, Quintanilla-López JE, Lebrón-Aguilar R, Martín-Álvarez PJ, Moreno-Arribas MV, Bartolomé B (2012) In vitro fermentation of a red wine extract by human gut microbiota: changes in microbial groups and formation of phenolic metabolites. J Agric Food Chem 60:2136-2147. doi:10.1021/jf2040115

67. Queipo-Ortuño MI, Boto-Ordóñez M, Murri M, GomezZumaquero JM, Clemente-Postigo M, Estruch R, Cardona Diaz F, Andrés-Lacueva C, Tinahones FJ (2012) Influence of red wine polyphenols and ethanol on the gut microbiota ecology and biochemical biomarkers. Am J Clin Nutr 95(6):1323-1334. doi:10.3945/ajen.111.027847

68. Bustos I, García-Cayuela T, Hernández-Ledesma B, Peláez C, Requena T, Martínez-Cuesta MC (2012) Effect of flavan-3-ols on the adhesion of potential probiotic lactobacilli to intestinal cells. J Agric Food Chem 60(36):9082-9088. doi:10.1021/jf301133g

69. Puupponen-Pimiä R, Nohynek L, Meier C, Kähkönen M, Heinonen M, Hopia A, Oksman-Caldentey KM (2001) Antimicrobial properties of phenolic compounds from berries. J Appl Microbiol 90(4):494-507. doi:10.1046/j.1365-2672.2001.01271.x

70. Kim SH, Park M, Woo H, Tharmalingam N, Lee G, Rhee KJ, Eom YB, Han SI, Seo WD, Kim JB (2012) Inhibitory effects of anthocyanins on secretion of Helicobacter pylori CagA and VacA toxins. Int J Med Sci 9(10):838-842. doi:10.7150/ ijms.5094

71. Hidalgo M, Oruna-Concha MJ, Kolida S, Walton GE, Kallithraka S, Spencer JP, de Pascual-Teresa S (2012) Metabolism of anthocyanins by human gut microflora and their influence on gut bacterial growth. J Agric Food Chem 60(15):38823890. doi:10.1021/jf3002153

72. Vivas N, Lonvaud-Funel A, Glories Y (1997) Effect of phenolic acids and anthocyanins on growth, viability and malolactic 
activity of a lactic acid bacterium. Food Microbiol 14:291-300. doi:10.1006/fmic.1996.0086

73. Howell AB (2007) Bioactive compounds in cranberries and their role in prevention of urinary tract infections. Mol Nutr Food Res 51:732-737. doi:10.1002/mnfr.200700038

74. Foo LY, Lu Y, Howell AB, Vorsa N (2000) The structure of cranberry proanthocyanidins which inhibit adherence of uropathogenic P-fimbriated Escherichia coli in vitro. Phytochemistry 54:173-181. doi:10.1016/S0031-9422(99)00573-7

75. Howell AB, Reed JD, Krueger CG, Winterbottom R, Cunningham DG, Leahy M (2005) A-type cranberry proanthocyanidins and uropathogenic bacterial anti-adhesion activity. Phytochemistry 66(18):2281-2291. doi:10.1016/j.phytochem.2005.05.022

76. Candela M, Maccaferri S, Turroni S, Carnevali P, Brigidi P (2010) Functional intestinal microbiome, new frontiers in prebiotic design. Int J Food Microbiol 140:93-101. doi:10.1016/j. ijfoodmicro.2010.04.017

77. Flint HJ (2012) The impact of nutrition on the human microbiome. Nutr Rev 70(Suppl 1):S10-S13. doi:10.1111/j.1753-4887.2012.00499.x

78. Flint HJ, Scott KP, Duncan SH, Louis P, Forano E (2012) Microbial degradation of complex carbohydrates in the gut. Gut Microbes 3(4):289-306. doi:10.4161/gmic. 19897

79. Canani RB, Costanzo MD, Leone L, Pedata M, Meli R, Calignano A (2011) Potential beneficial effects of butyrate in intestinal and extraintestinal diseases. World J Gastroenterol 17(12):1519-1528. doi:10.3748/wjg.v17.i12.1519

80. Roberfroid M, Gibson GR, Hoyles L, McCartney AL, Rastall R, Rowland I, Wolvers D, Watzl B, Szajewska H, Stahl B, Guarner F, Respondek F, Whelan K, Coxam V, Davicco MJ, Léotoing L, Wittrant Y, Delzenne NM, Cani PD, Neyrinck AM, Meheust A (2010) Prebiotic effects: metabolic and health benefits. Br J Nutr 104(Suppl. 2):S1-S63. doi:10.1017/S0007114510003363

81. Gibson GR, Roberfroid MB (1995) Dietary modulation of the human colonic microbiota: introducing the concept of prebiotics. J Nutr 125(6):1401-1412

82. Gibson GR, Probert HM, Loo JV, Rastall RA, Roberfroid MB (2004) Dietary modulation of the human colonic microbiota: updating the concept of prebiotics. Nutr Res Rev 17:259-275. doi:10.1079/NRR200479

83. Ito M, Deguchi Y, Matsumoto K, Kimura M, Onodera N, Yajima $\mathrm{T}$ (1993) Influence of galactooligosaccharides on the human fecal microflora. J Nutr Sci Vitaminol (Tokyo) 39(6):635-640

84. Rowland IR, Tanaka R (1993) The effects of transgalactosylated oligosaccharides on gut flora metabolism in rats associated with a human faecal microflora. J Appl Bacteriol 74(6):667-674. doi:10.1111/j.1365-2672.1993.tb05201.x

85. Bouhnik Y, Flourié B, D'Agay-Abensour L, Pochart P, Gramet G, Duran M, Rambaud J-C (1997) Administration of transgalacto-oligosaccharides increases fecal bifidobacteria and modifies colonic fermentation metabolism in healthy humans. $\mathbf{J}$ Nutr 127:444-448

86. Boehm G, Lidestri M, Casetta P, Jelinek J, Negretti F, Stahl B, Marini A (2002) Supplementation of a bovine milk formula with an oligosaccharide mixture increases counts of fecal bifidobacteria in preterm infants. Arch Dis Child Fetal Neonatal Ed 86(3):F178-F181. doi:10.1136/fn.86.3.F178

87. Ito $\mathrm{Y}$, Moriwaki $\mathrm{H}$, Muto $\mathrm{Y}$, Kato $\mathrm{N}$, Watanabe $\mathrm{K}$, Ueno $\mathrm{K}$ (1997) Effect of lactulose on short-chain fatty acids and lactate production and on the growth of faecal flora, with special reference to Clostridium difficile. J Med Microbiol 46(1):80-84. doi:10.1099/00222615-46-1-80

88. Gibson GR, Beatty ER, Wang X, Cummings JH (1995) Selective stimulation of bifidobacteria in the human colon by oligofructose and inulin. Gastroenterology 108(4):975-982. doi:10.1016/0016-5085(95)90192-2
89. Kleessen B, Sykura B, Zunft HJ, Blaut M (1997) Effects of inulin and lactose on fecal microflora, microbial activity, and bowel habit in elderly constipated persons. Am J Clin Nutr 65(5):1397-1402

90. Langlands SJ, Hopkins MJ, Coleman N, Cummings JH (2004) Prebiotic carbohydrates modify the mucosa associated microflora of the human large bowel. Gut 53(11):1610-1616. doi:10.1136/gut.2003.037580

91. Duncan SH, Louis P, Flint HJ (2004) Lactate-utilizing bacteria, isolated from human feces, that produce butyrate as a major fermentation product. Appl Environ Microbiol 70(10):5810-5817. doi:10.1128/AEM.70.10.5810-5817

92. Belenguer A, Duncan SH, Calder AG, Holtrop G, Louis P, Lobley GE, Flint HJ (2006) Two routes of metabolic cross-feeding between Bifidobacterium adolescentis and butyrate-producing anaerobes from the human gut. Appl Environ Microbiol 72(5):3593-3599. doi:10.1128/AEM.72.5.3593-3599.2006

93. Kankaanpää P, Yang B, Kallio H, Isolauri E, Salminen S (2004) Effects of polyunsaturated fatty acids in growth medium on lipid composition and on physicochemical surface properties of lactobacilli. Appl Environ Microbiol 70(1):129-136. doi:10.1128/AEM.70.1.129-136.2004

94. Gorissen L, De Vuyst L, Raes K, De Smet S, Leroy F (2012) Conjugated linoleic and linolenic acid production kinetics by bifidobacteria differ among strains. Int $\mathrm{J}$ Food Microbiol 155(3):234-240. doi:10.1016/j.ijfoodmicro.2012.02.012

95. Wahle KW, Heys SD, Rotondo D (2004) Conjugated linoleic acids: are they beneficial or detrimental to health? Prog Lipid Res 43(6):553-587. doi:10.1016/j.plipres.2004.08.002

96. Ross RP, Mills S, Hill C, Fitzgerald GF, Stanton C (2010) Specific metabolite production by gut microbiota as a basis for probiotic function. Int Dairy J 20(4):269-276. doi:10.1016/j. idairyj.2009.12.003

97. Possemiers S, Bolca S, Verstraete W, Heyerick A (2011) The intestinal microbiome: a separate organ inside the body with the metabolic potential to influence the bioactivity of botanicals. Fitoterapia 82:53-66. doi:10.1016/j.fitote.2010.07.012

98. Hervert-Hernández D, Goñi I (2011) Dietary polyphenols and human gut microbiota: a review. Food Rev Int 27(2):154-169. doi:10.1080/87559129.2010.535233

99. Young IS, Woodside JV (2001) Antioxidants in health and disease. J Clin Pathol 54:176-186. doi:10.1136/jcp.54.3.176

100. Willcox JK, Ash SL, Catignani GL (2004) Antioxidants and prevention of chronic disease. Crit Rev Food Sci Nutr 44:275295. doi:10.1080/10408690490468489

101. Zafra-Stone S, Yasmin T, Bagchi M, Chatterjee A, Vinson JA, Bagchi D (2007) Berry anthocyanins as novel antioxidants in human health and disease prevention. Mol Nutr Food Res 51(6):675-683. doi:10.1002/mnfr.200700002

102. Wang LS, Stoner GD (2008) Anthocyanins and their role in cancer prevention. Cancer Lett 269(2):281-290. doi:10.1016/j. canlet.2008.05.020

103. Wang XL, Kim HJ, Kang SI, Kim SI, Hur HG (2007) Production of phytoestrogen S-equol from daidzein in mixed culture of two anaerobic bacteria. Arch Microbiol 187(2):155-160. doi:10.1007/s00203-006-0183-8

104. Yokoyama S, Niwa T, Osawa T, Suzuki T (2010) Characterization of an O-desmethylangolensin-producing bacterium isolated from human feces. Arch Microbiol 192(1):15-22. doi:10.1007/ s00203-009-0524-5

105. Yokoyama S, Suzuki T (2008) Isolation and characterization of a novel equol-producing bacterium from human feces. Biosci Biotechnol Biochem 72(10):2660-2666. doi:10.1271/ bbb. 80329

106. Matthies A, Blaut M, Braune A (2009) Isolation of a human intestinal bacterium capable of daidzein and 
genistein conversion. Appl Environ Microbiol 75(6):17401744. doi:10.1128/AEM.01795-08

107. Raimondi S, Roncaglia L, De Lucia M, Amaretti A, Leonardi A, Pagnoni UM, Rossi M (2009) Bioconversion of soy isoflavones daidzin and daidzein by Bifidobacterium strains. Appl Microbiol Biotechnol 81(5):943-950. doi:10.1007/s00253-008-1719-4

108. Setchell KD, Clerici C (2010) Equol: history, chemistry, and formation. J Nutr 140(7):1355S-1362S. doi:10.3945/ jn.109.119776

109. Setchell KD, Clerici C (2010) Equol: pharmacokinetics and biological actions. J Nutr 140(7):1363S-1368S. doi:10.3945/ jn.109.119784

110. Frankenfeld CL, Atkinson C, Thomas WK, Gonzalez A, Jokela T, Wähälä K, Schwartz SM, Li SS, Lampe JW (2005) High concordance of daidzein-metabolizing phenotypes in individuals measured 1-3 years apart. Br J Nutr 94(6):873-876. doi:10.1079/BJN20051565

111. Yuan JP, Wang JH, Liu X (2007) Metabolism of dietary soy isoflavones to equol by human intestinal microflora-implications for health. Mol Nutr Food Res 51(7):765-781. doi:10.1002/ mnfr.200600262

112. Setchell KD, Clerici C, Lephart ED, Cole SJ, Heenan C, Castellani D, Wolfe BE, Nechemias-Zimmer L, Brown NM, Lund TD, Handa RJ, Heubi JE (2005) S-equol, a potent ligand for estrogen receptor beta, is the exclusive enantiomeric form of the soy isoflavone metabolite produced by human intestinal bacterial flora. Am J Clin Nutr 81(5):1072-1079

113. Hwang CS, Kwak HS, Lim HJ, Lee SH, Kang YS, Choe TB, Hur HG, Han KO (2006) Isoflavone metabolites and their in vitro dual functions: they can act as an estrogenic agonist or antagonist depending on the estrogen concentration. J Steroid Biochem Mol Biol 101:246-253. doi:10.1016/j. jsbmb.2006.06.020

114. Chang YC, Nair MG, Nitiss JL (1995) Metabolites of daidzein and genistein and their biological activities. J Nat Prod 58:1901-1905. doi:10.1021/np50126a016

115. Lund TD, Blake C, Bu L, Hamaker AN, Lephart ED (2011) Equol an isoflavonoid: potential for improved prostate health, in vitro and in vivo evidence. Reprod Biol Endocrinol 9:4. doi:10.1186/1477-7827-9-4 http://www.rbej.com/content/9/1/4 Accessed 19 Dec 2014

116. Kang NJ, Lee KW, Rogozin EA, Cho YY, Heo YS, Bode AM, Lee HJ, Dong Z (2007) Equol, a metabolite of the soybean isoflavone daidzein, inhibits neoplastic cell transformation by targeting the MEK/ERK/p90RSK/activator protein-1 pathway. J Biol Chem 282(45):32856-32866. doi:10.1074/jbc. M701459200

117. Zheng W, Zhang Y, Ma D, Shi Y, Liu C, Wang P (2012) ( \pm ) Equol inhibits invasion in prostate cancer DU145 cells possibly via down-regulation of matrix metalloproteinase-9, matrix metalloproteinase-2 and urokinase-type plasminogen activator by antioxidant activity. J Clin Biochem Nutr 51(1):61-67. doi:10.3164/jcbn.11-54

118. Kang JS, Yoon YD, Han MH, Han SB, Lee K, Park SK, Kim HM (2007) Equol inhibits nitric oxide production and inducible nitric oxide syn-thase gene expression through down-regulating the activation of Akt. Int Immunopharmacol 7:491-499. doi:10.1016/j.intimp.2006.12.004

119. Clavel T, Henderson G, Alpert CA, Philippe C, Rigottier-Gois L, Dore J, Blaut M (2005) Intestinal bacterial communities that produce active estrogen-like compounds enterodiol and enterolactone in humans. Appl Environ Microbiol 71:6077-6085. doi:10.1128/AEM.71.10.6077-6085.2005

120. Landete JM (2012) Plant and mammalian lignans: a review of source, intake, metabolism, intestinal bacteria and health. Food Res Int 46(1):410-424. doi:10.1016/j.foodres.2011.12.023
121. Högger P (2013) Nutrition-derived bioactive metabolites produced by gut microbiota and their potential impact on human health. Nutr Med 1(1):1 http://www.nume.de/index.php/nume/ article/view/1/4. Accessed 24 Apr 2014

122. Wang LQ (2002) Mammalian phytoestrogens: enterodiol and enterolactone. J Chromatogr B 777(1-2):289-309. doi:10.1016/ S1570-0232(02)00281-7

123. Brunelli E, Minassi A, Appendino G, Moro L (2007) 8-Prenylnaringenin, inhibits estrogen receptor-alpha mediated cell growth and induces apoptosis in MCF-7 breast cancer cells. J Steroid Biochem Mol Biol 107:140-148. doi:10.1016/j. jsbmb.2007.04.003

124. Nunes C, Almeida L, Laranjinha J (2005) Synergistic inhibition of respiration in brain mitochondria by nitric oxide and dihydroxyphenylacetic acid (DOPAC). Implications for Parkinson's disease. Neurochem Int 47(3):173-182. doi:10.1016/j. neuint.2005.03.005

125. Nunes C, Almeida L, Laranjinha J (2008) 3,4-Dihydroxyphenylacetic acid (DOPAC) modulates the toxicity induced by nitric oxide in PC-12 cells via mitochondrial dysfunctioning. Neurotoxicology 29(6):998-1007. doi:10.1016/j.neuro.2008.07.003

126. Nunes C, Barbosa RM, Almeida L, Laranjinha J (2011) Nitric oxide and DOPAC-induced cell death: from GSH depletion to mitochondrial energy crisis. Mol Cell Neurosci 48(1):94-103. doi:10.1016/j.men.2011.06.009

127. Appeldoorn MM, Vincken JP, Aura AM, Hollman PCH, Gruppen $H$ (2009) Procyanidin dimers are metabolized by human microbiota with 2-(3,4-dihydroxyphenyl)acetic acid and 5-(3,4-Dihydroxyphenyl)- $\gamma$-valerolactone as the major metabolites. J Agric Food Chem 57(3):1084-1092. doi:10.1021/ jf803059z

128. Galati G, O’Brien PJ (2004) Potential toxicity of flavonoids and other dietary phenolics: significance for their chemopreventive and anticancer properties. Free Radic Biol Med 37(3):287-303. doi:10.1016/j.freeradbiomed.2004.04.034

129. Bailey DG, Arnold MO, Spence D (1998) Grapefruit juice-drug interactions. $\mathrm{Br} \mathrm{J}$ Clin Pharmacol 46:101-110. doi:10.1046/j.1365-2125.1998.00764.x

130. Castañeda-Ovando A, Pacheco-Hernández M, Páez-Hernández ME, Rodríguez JA, Galán-Vidal CA (2009) Chemical studies of anthocyanins: a review. Food Chem 113(4):859-871. doi:10.1016/j.foodchem.2008.09.001

131. Faria A, Fernandes I, Norberto S, Mateus N, Calhau C (2014) Interplay between anthocyanins and gut microbiota. J Agric Food Chem 62(29):6898-6902. doi:10.1021/jf501808a

132. Keppler K, Humpf HU (2005) Metabolism of anthocyanins and their phenolic degradation products by the intestinal microflora. Bioorg Med Chem 13(17):5195-5205. doi:10.1016/j. bmc.2005.05.003

133. Seeram NP, Bourquin LD, Nair MG (2001) Degradation products of cyanidin glycosides from tart cherries and their bioactivities. J Agric Food Chem 49(10):4924-4929. doi:10.1021/ jf0107508

134. Vitaglione P, Donnarumma G, Napolitano A, Galvano F, Gallo A, Scalfi L, Fogliano V (2007) Protocatechuic acid is the major human metabolite of cyanidin-glucosides. J Nutr 137(9):2043-2048

135. Masella R, Santangelo C, D'Archivio M, Li Volti G, Giovannini C, Galvano F (2012) Protocatechuic acid and human disease prevention: biological activities and molecular mechanisms. Curr Med Chem 19(18):2901-2917. doi: $10.2174 / 092986712800672102$

136. Wang D, Wei X, Yan X, Jin T, Ling W (2010) Protocatechuic acid, a metabolite of anthocyanins, inhibits monocyte adhesion and reduces atherosclerosis in apolipoprotein E-deficient mice. J Agric Food Chem 58:12722-12728. doi:10.1021/jf103427j 
137. Williamson G, Clifford MN (2010) Colonic metabolites of berry polyphenols: the missing link to biological activity? $\mathrm{Br} \mathbf{J}$ Nutr 104(Suppl 3):S48-S66. doi:10.1017/S0007114510003946

138. Bokkenheuser VD, Shacketon CHL, Winter J (1987) Hydrolysis of dietary flavonoid glycosides by strains of intestinal bacteroides from humans. Biochem J 248:953-956

139. Terao J (2010) Flavonols: Metabolism, Bioavailability, and Health Impacts. In: Fraga CG (ed) Plant phenolics and human health: biochemistry, nutrition, and pharmacology. Wiley Inc, Hoboken, pp 185-196

140. Forester SC, Waterhouse AL (2010) Gut metabolites of anthocyanins, gallic acid, 3-O-methylgallic acid, and 2,4,6-trihydroxybenzaldehyde, inhibit cell proliferation of Caco- 2 cells. $\mathbf{J}$ Agric Food Chem 58(9):5320-5327. doi:10.1021/jf9040172

141. Verzelloni E, Pellacani C, Tagliazucchi D, Tagliaferri S, Calani L, Costa LG, Brighenti F, Borges G, Crozier A, Conte A, Del Rio D (2011) Antiglycative and neuroprotective activity of colon-derived polyphenol catabolites. Mol Nutr Food Res 55(Suppl 1):S35-S43. doi:10.1002/mnfr.201000525

142. Day AJ, Bao Y, Morgan MR, Williamson G (2000) Conjugation position of quercetin glucuronides and effect on biological activity. Free Radic Biol Med 29(12):1234-1243. doi:10.1016/ S0891-5849(00)00416-0

143. Kawai Y, Nishikawa T, Shiba Y, Saito S, Murota K, Shibata N, Kobayashi M, Kanayama M, Uchida K, Terao J (2008) Macrophage as a target of quercetin glucuronides in human atherosclerotic arteries: implication in the anti-atherosclerotic mechanism of dietary flavonoids. J Biol Chem 283(14):9424-9434. doi:10.1074/jbc.M706571200

144. Scholz-Ahrens KE, Ade P, Marten B, Weber P, Timm W, Açil Y, Glüer CC, Schrezenmeir J (2007) Prebiotics, probiotics, and synbiotics affect mineral absorption, bone mineral content, and bone structure. J Nutr 137(3 Suppl 2):838S-846S

145. LeBlanc JG, Milani C, de Giori GS, Sesma F, van Sinderen D, Ventura M (2013) Bacteria as vitamin suppliers to their host: a gut microbiota perspective. Curr Opin Biotechnol 24(2):160168. doi:10.1016/j.copbio.2012.08.005

146. LeBlanc JG, de Giori GS, Smid EJ, Hugenholtz J, Sesma F (2007) Folate production by lactic acid bacteria and other food-grade microorganisms. In: Mendez-Vilas A (ed) Communicating current research and educational topics and trends in applied microbiology, microbiology series No. 1, vol 1, Formatex, Badajos, Spain, pp 329-339
147. Pompei A, Cordisco L, Amaretti A, Zanoni S, Matteuzzi D, Rossi M (2007) Folate production by bifidobacteria as a potential probiotic property. Appl Environ Microbiol 73(1):179-185. doi:10.1128/AEM.01763-06

148. Rossi M, Amaretti A, Raimondi S (2011) Folate production by probiotic bacteria. Nutrients 3(1):118-134. doi:10.3390/ nu3010118

149. Hill MJ (1997) Intestinal flora and endogenous vitamin synthesis. Eur J Cancer Prev 6(Suppl 1):S43-S45. doi:10.1097/00008469-199703001-00009

150. Ramotar K, Conly JM, Chubb H, Louie TJ (1984) Production of menaquinones by intestinal anaerobes. J Infect Dis 150(2):213218. doi:10.1093/infdis/150.2.213

151. Mathers JC, Fernandez F, Hill MJ, McCarthy PT, Shearer MJ, Oxley A (1990) Dietary modification of potential vitamin K supply from enteric bacterial menaquinones in rats. Br J Nutr 63(3):639-652. doi:10.1079/BJN19900150

152. Millette M, Dupont C, Archambault D, Lacroix M (2007) Partial characterization of bacteriocins produced by human Lactococcus lactis and Pediococccus acidilactici isolates. J Appl Microbiol 102(1):274-282. doi:10.1111/j.1365-2672.2006.03044.x

153. Millette M, Cornut G, Dupont C, Shareck F, Archambault D, Lacroix M (2008) Capacity of human nisin- and pediocinproducing lactic acid bacteria to reduce intestinal colonization by vancomycin-resistant enterococci. Appl Environ Microbiol 74(7):1997-2003. doi:10.1128/AEM.02150-07

154. Björksten B, Naaber P, Sepp E, Mikelsaar M (1999) The intestinal microflora in allergic Estonian and Swedish 2-year-old children. Clin Exp Allergy 29(3):342-346. doi:10.1046/j.1365-2222.1999.00560.x

155. McGarr SE, Ridlon JM, Hylemon PB (2005) Diet, anaerobic bacterial metabolism, and colon cancer: a review of the literature. J Clin Gastroenterol 39(2):98-109

156. Serra A, Macia A, Romero M, Reguant J, Ortega N, Motilva M (2012) Metabolic pathways of the colonic metabolism of flavonoids (flavonols, flavones and flavanones) and phenolic acids. Food Chem 130:383-393. doi:10.1016/j.foodchem.2011.07.055

157. Peng X, Zhang Z, Zhang N, Liu L, Li S, Wei H (2014) In vitro catabolism of quercetin by human fecal bacteria and the antioxidant capacity of its catabolites. Food Nutr Res 58:23406. doi:10.3402/fnr.v58.23406 